\title{
Chronic upper airway inflammation and systemic oxidative stress from nanoparticles in photocopier operators: Mechanistic insights
}

\author{
Madhu Khatri, ${ }^{1}$ Dhimiter Bello, ${ }^{2,3 *}$ John Martin, ${ }^{2}$ Anila Bello, ${ }^{2}$ Rebecca Gore, ${ }^{2}$ Philip \\ Demokritou, ${ }^{3}$ Peter Gaines ${ }^{4}$
}

${ }^{1}$ Department of Biotechnology Engineering, UIET, Panjab University, Chandigarh -160014, India; ${ }^{2}$ Department of Public Health, University of Massachusetts Lowell, One University Avenue, Lowell, MA 01854. ${ }^{3}$ Harvard Center for Nanotechnology and Nanotoxicology, Department of Environmental Health, Harvard T.H. Chan School of Public Health, Boston, MA

02115. ${ }^{4}$ Department of Biology, University of Massachusetts Lowell, One University Avenue, Lowell, MA 01854.

*Corresponding author

Dhimiter Bello, ScD, MSc

Assoc. Prof., Dept. Public Health,

College of Health Sciences

One University Avenue, Lowell, MA 01854.

E-mail: dhimiter_bello@uml.edu; Tel.: + 1-978 934-3343 


\section{Authors E-mail:}

Madhu Khatri- madhuk@pu.ac.in, John Martin- martin-j@comcast.net, Anila BelloAnila_Bello@uml.edu, Rebecca Gore- Rebecca_Gore@uml.edu, Philip Demokritoupdemokri@hsph.harvard.edu, Peter Gaines-peter_gaines@uml.edu 


\begin{abstract}
Background: Several recent studies have linked emissions from printing equipment with upper airway inflammation and systemic oxidative stress in healthy humans, lung inflammation in mice, and cytotoxicity, induction of inflammatory markers and epigenetic changes in human cell lines. Acute exposures have lead to upper airway inflammation and systemic oxidative stress, which for certain markers took longer than 24-36 h post-exposure to clear.
\end{abstract}

Objective: In this follow-up work, we determined: i) whether chronic exposures to nanoparticles from copiers lead to chronic upper airway inflammation and systemic oxidative stress; and ii) whether expression patterns of biomarkers for such stresses change during transition from acute to chronic exposures.

Methods: Six permanent employees from three copy centers and eleven controls participated in the study. Nasal lavage and urine samples were collected on Monday morning (pre-shift, MoAM) and evening (post-shift, Mo-PM), as well as at the end of the workweek (Fr-PM), over three random weeks. The matched controls were sampled over one week. Nasal lavage samples were analyzed for a panel of 14 pro-inflammatory cytokines/chemokines, inflammatory cells, and total protein. Urine samples were analyzed for $8-O H-d G$, a biomarker of systemic oxidative stress. Detailed quantitative exposure assessment to airborne nanoparticles was conducted for a whole week, and included size distribution, size-fractionated aerosol collection, extensive chemical analysis, and lung burden estimates.

Results: The daily geometric mean total particle number concentration varied between 14,600 21,860 particles $/ \mathrm{cm}^{3}, 1.7-12.1$ times greater than background, with maxima up to 143,000 particles $/ \mathrm{cm}^{3}$. Mass concentration of the nanoscale fraction was in the $1-10 \mu \mathrm{g} / \mathrm{m}^{3}$ range. 
Chemical composition of the nanoparticle fraction was comprised mostly of organic compounds, mixed with several engineered nanoparticles, which contributed a metal content ranging from 2$8 \%$ of the total particulate mass.

Five out of the 14 inflammatory cytokines, namely IL-6, IL-8, TNF $\alpha$, IL-1 $\beta$ and Eotaxin, were significantly elevated in the nasal lavage samples of the chronically exposed copier operators ( $p$ $<0.0001$ ) relative to controls. One cytokine, G-CSF, was significantly down regulated (p < $0.0001)$ in copier operators $(\mathrm{p}<0.05)$. The level of all six cytokines did not change significantly across days (i.e. Mo-AM vs. Mo-PM, and Mo-AM vs. Fr-PM) and across weeks in chronically exposed individuals. In addition, there were significant $(\mathrm{p}<0.0001)$ increases in inflammatory cell infiltration (2.7 fold) in nasal lavage samples and $8-O H-d G$ in (4.3 fold) in urine samples.

Conclusion: Chronic upper airway inflammation and systemic oxidative stress were documented in photocopier operators chronically exposed to nanoparticles. These findings agree with the recent toxicological literature on printer-emitted particles and medical case reports, and call for an industry-wide study of the health effects resulting from exposure to printer-emitted particles in chronically exposed workers. Inflammatory markers point to possible involvement of toll-like receptors, particularly TLR-4, oxidative stress, and the Nf-kB pathway in mediating airway tissue inflammation.

Running head: Chronic upper airway inflammation and oxidative stress in copier operators Key Words: engineered nanoparticles, photocopiers, printers, inflammation, oxidative stress, toll-like receptors 


\section{INTRODUCTION}

Toner-based printing devices, namely laser printers and photocopiers, emit high levels of nanoparticles [1-3]. Printing and photocopying, like many other industries, have shifted fully to nano-enabled toner formulations that incorporate several engineered nanoparticles in toner and paper $[2,3]$. Exposures of photocopier operators are primarily to nanoparticles. Volatile organic compounds (VOCs and ozone), historically major contaminants emitted from photocopiers, have been reduced over the years as a result of toner re-formulations and other technological modifications [4]. Nanoparticles are at present the main contaminant emitted from photocopiers.

The airborne nanoscale fraction of emissions from copying equipment is a complex mixture. It contains incidental nanoparticles generated as a result of the condensation of semi-volatile organic compounds originating from thermal decomposition of the polymeric material of the toner, as well as engineered nanoparticles added to the toners [2]. Several engineered nanoparticles have been identified in toners, including among others iron oxide $\left(\mathrm{Fe}_{2} \mathrm{O}_{3}\right)$, titanium dioxide $\left(\mathrm{TiO}_{2}\right.$ ), silicon dioxide (fumed silica or $\mathrm{SiO}_{2}$ ), aluminum oxide (alumina or $\mathrm{Al}_{2} \mathrm{O}_{3}$ ), cerium oxide (ceria or $\mathrm{CeO}_{2}$ ), and oxides of copper $(\mathrm{Cu})$, manganese $(\mathrm{Mn})$, and nickel $(\mathrm{Ni})$. Chronic health effects of such nanoparticle exposures in full-time copier operators and frequent printer users have not been studied and, mechanistically, remain poorly understood, in part because responses associated with repeated exposures has received attention only in the past few years. In this paper, we will refer to photocopiers and printers collectively as toner-based hard copy devices. Indeed, we have shown in two separate studies $[2,3]$ that emissions from such devices are chemically and morphologically quite similar, and the only major difference between the two technologies is the volume of printing or photocopying, i.e. the resulting exposure profiles. 
In an earlier paper, we demonstrated that acute exposures to nanoparticles from photocopying leads to acute upper airway inflammation and systemic oxidative stress in young, healthy volunteers [5]. In that study, a single exposure episode of up to six hours with a daily average exposure of 20,000 to 30,000 particles $/ \mathrm{cm}^{3}$ triggered a notable increase 6-h post-exposure of several inflammatory markers in the nasal lavage, including interlukin-6 (IL-6), interlukin-8 (IL8), tumor necrosis factor $\alpha(\mathrm{TNF} \alpha)$, interlukin-1 $\beta$ (IL-1 $\beta)$, granulocyte- colony stimulating factor (G-CSF), epidermal growth factor (EGF), interlukin-10 (IL-10), monocyte chemoattractant protein-1 (MCP1), fractalkine and vascular endothelial growth factor (VEGF). Most of these cytokines - TNF $\alpha$, IL-1 $\beta$, G-CSF, IL-10, MCP1 and VEGF - reached baseline levels within 24$36 \mathrm{hrs,}$ whereas four cytokines - IL-6, IL-8, EGF, and fractalkine - remained elevated even $30 \mathrm{~h}$ post-exposure. Urinary 8-hydroxy-2'-deoxyguanosine (8-OH $d G$ ), a marker of systemic oxidative stress, as well as neutrophil infiltration and total protein in the nasal lavage also increased $6 \mathrm{~h}$ post-exposure and returned to pre-exposure level by $30 \mathrm{~h}$ post-exposure. These responses exhibited similar profiles to those of cytokines. Based on such acute responses, one would hypothesize that chronic exposures to nanoparticles from hard copy devices could trigger development of chronic inflammation. These increased inflammatory and oxidative stress responses in humans were recapitulated in three human cell types exposed to the same particles differentiated THP-1 macrophages, primary small airway bronchial cells, and primary nasal airway cells [6]. Pulmonary inflammation was also observed in vivo in Balb/c mice [7]. It was further shown in THP-1 macrophages that photocopier nanoparticles induced increased transcription of inflammatory (TNF- $\alpha$ ) genes, oxidative stress genes (HO-1, GPX1, SOD1), and apoptotic (p53, CASP8) genes [6]. More recently, Pirela et al. [8] used several cell lines (specifically THP-1 macrophages, small airway epithelial cells (SAEC), and lymphoblasts 
(TAC6)) exposed to a range of doses relevant to consumer exposures and found increased cellular toxicity plus increased expression of pro-inflammatory cytokines/chemokines and intracellular oxidative stress, as well as modest epigenetic modifications. Of note, we have shown in-vitro and in-vivo that copier nanoparticles are significantly more potent than micronsized copier particles or $30 \mathrm{~nm}$ copper oxide nanoparticles, and comparable to or even more potent than welding fumes and diesel exhaust in inducing cytotoxicity, inflammatory markers, and lung injury $[3,6,7,9]$.

There is understandably great interest in studying the effects of these nanoparticle exposures in the lower airways and other extra-pulmonary organs (as examples liver, kidneys, hematopoietic and nervous systems). Indeed, most of the existing studies on engineered nanoparticles in workplaces, or ultrafine air pollution, do focus on deep airways and circulatory markers [10, 11]. However, the upper airways are often overlooked. The cellular responses of the tissues in the upper airways to nanoparticles are of great interest for two major reasons. First, the upper airways are implicated directly in rhinitis, airway hyperreactivity, and other inflammatory conditions and diseases [12]. Secondly, the cells in the upper airways cross-talk with other cell types in the lower airways, exacerbating or sustaining inflammation [12-15]. Of particular interest for human exposures to nanoparticles is the possible role of the olfactory bulb in nanoparticle uptake and translocation towards the brain. Anosmia, or loss of the sense of smell, and hyposmia (reduced smell sensation) are well-known conditions among photocopier operators, which historically has been attributed to ozone and volatile organic compounds (VOCs). However, this may not be the case, since technological innovations in the design of hard copy devices and the toner formulations have reduced both ozone and VOCs exposures [16,17]. 
Nanoparticles are now the major exposure source from hard copy devices and the main suspect agent.

Currently, the temporal dynamics of airway inflammation following chronic nanoparticle exposures, the exact molecular mechanisms involved in the cellular responses, and the fluctuations in levels of such inflammatory/injury markers under repeated, realistic exposures are poorly understood.

The main objective of this work is two-fold. First, the study aimed to establish that chronic exposures to nanoparticles from copy equipment can lead to chronic upper airway inflammation and chronic oxidative stress. We focused on markers of inflammation collected from nasal lavage and markers of oxidative stress in urine samples, in part because of the matched endpoints from acute human exposures and in-vitro studies. Second, the work aimed to better understand the within- and between-person variability in the expression levels of inflammatory biomarkers. This second aim of the study is helpful in gaining mechanistic insights into the mode of action of these nanoparticles, understanding inter-individual susceptibility, and in identifying optimal sampling schemes for large-scale human studies.

\section{METHODS}

\section{Study population and recruitment:}

We targeted full-time photocopy operators chronically exposed to nanoparticles from commercial photocopying as part of their job. Subjects were recruited by distributing flyers in commercial photocopy centers in the Northeast United States. Detailed presentations on the project were given for the interested individuals. Six operators from three commercial photocopying centers agreed to participate in the study. Eleven controls (individuals not involved 
with routine photocopying or printing activities, and with minimal exposure to nanoparticles from copying equipment) were also recruited at the same time. These controls were selected from employees in the same building as the photocopier operators and met the following criteria: i) adults over the age of 18; ii) non-smokers; iii) not suffering from flu, allergies, or asthma at the time of the study; iii) not taking any anti-inflammatory medication, especially nasal sprays or drops at the time of the study; and iv) not-pregnant (if women). The chronically exposed workers had to be full-time employees of commercial copy centers, defined as centers with at least one full-time employee, whose primary job was printing and photocopying. These employees had been working from 2 to 15 years in this job. Similarly, they should not be suffering from flu during the study week. By design, we preferred to recruit only non-smoking operators. Five of the six operators met this criterion. The sixth operator, a female smoker and an enthusiastic participant, was allowed to participate in this pilot study. The impact of smoking on study outcome is discussed later. Copy center participants were asked to fill out a brief questionnaire about their age, gender, respiratory health status, use of medications, and the potential nonoccupational exposures to (copier and printer emitted) nanoparticles. The study was approved by the institutional review board of the University of Massachusetts Lowell (IRB Protocol \#: 09117-BEL-XPD).

Chronically exposed copier operators: Nasal lavage and urine samples were collected on Monday morning pre-shift (Mo-AM) and post-shift (Mo-PM), as well as at the end of the workweek (Friday post-shift or Fr-PM), yielding 3 samples per individual per week for 3 weeks (nine/individual). Each copier operator was sampled for three random weeks over the course of two years in order to assess variability in these effect biomarkers. One copier operator decided to drop out in the middle of the study and was sampled for only one week. 
Controls: Healthy volunteers who met the criteria described earlier were recruited to serve as controls. As with the exposed group, these controls were asked to give 3 nasal lavage and 3 urine samples during the course of one week (Monday pre-and post-shift and Friday post-shift, e.g. Mo-AM, Mo-PM, and Fr-PM) chosen randomly over the course of the study.

Exposure Characterization: Commercial photocopying centers are often small businesses, commonly employing between 1 and 3 full time employees [2]. Detailed information was collected for each copy center by certified occupational hygienists, and included: physical layout and geographic location of the center, ventilation type and rates, number and type of copiers, workload activities, and other indoor air quality parameters.

Exposure characterization included real-time and integrated sampling for detailed physicochemical analysis. Real-time instruments were used to monitor size distribution and total number concentration of airborne particulate matter in the copy center environment of the chronically exposed population. Since validated personal monitors for nanoparticles were lacking at the time of this study and are still not widely used, we relied on area monitoring instrumentation and integrated sampling as described in detail in earlier work [1,2]. The inlets of these instruments were positioned at breathing zone height in a location where the employee spent the majority of the working day time. Instrumentation used for airborne nanoparticle monitoring included: $i$ ) a Fast Mobility Particle Sizer (TSI Inc, FMPS Model 3091, 5.6-560 nm range, $1 \mathrm{sec}$ response time); ii) an Aerodynamic Particle Sizer (TSI Inc., APS Model 3321, 0.5-20 $\mu \mathrm{m}$ range, $1 \mathrm{sec}$ response time); and iii) a Condensation Particle Counter (TSI Inc., CPC Model 3007, total number concentration in $0.1-1 \mu \mathrm{m}, 1 \mathrm{sec}$ response time). Size selective sampling of airborne particulate matter was conducted with the Harvard cascade impactor $(30 \mathrm{~L} / \mathrm{min})$ for a whole week during one of the three study weeks. Each fraction $\left(\mathrm{PM}_{0.1}, \mathrm{PM}_{0.1-2.5}\right.$, and $\left.\mathrm{PM}_{2.5-10}, \mu \mathrm{m}\right)$ was 
analyzed gravimetrically for total mass. Chemical analysis included: total and water-soluble fraction of a panel of $\sim 50$ metals/elements by inductively coupled plasma mass spectrometry (ICP-MS); organic and elemental carbon content, soluble ions, and organic functional group characterization, as described in Bello et al. [1] and Martin et al. [2].

Controls were sampled in their work environment (offices). The range of daily mean total particle number concentration for controls was 1200 to 7600 particles $/ \mathrm{cm}^{3}$.

Nasal lavage sampling technique: Nasal lavage (NL) was performed according to our previously published procedure [4] and is briefly summarized here for clarity. The nasal cavity was misted over with saline and the liquid was aspirated back using a mucous trap tube connected with an evacuator. The NL procedure was repeated twice (yielding, based on recovery studies, $\sim 93 \%$ of total recoverable cytokines from three subsequent NL procedures) [5].

Sample Processing: Following collection, the specimens were immediately cooled on ice in the field and transported within 30 min to the laboratory, where they were immediately vortexed for $15 \mathrm{sec}$ and centrifuged at $500 \times g$ for $10 \mathrm{~min}$ at $4^{\circ} \mathrm{C}$. A protease inhibitor cocktail $0.01 \% \mathrm{v} / \mathrm{v}$ was added to the supernatant, and the sample was then stored at $-80^{\circ} \mathrm{C}$ until further analysis. The pellet of cells was resuspended in $250 \mu \mathrm{L}$ of phosphate-buffered saline (PBS), supplemented with $0.1 \% \mathrm{v} / \mathrm{v}$ bovine serum albumin (BSA) and $0.1 \%$ mucus lysine solution. This cell suspension was used to obtain total cell count and cell differentials. Total cell count was obtained using a Neubauer's hemocytometer. For differential cell counts, smears were obtained from $75-100 \mu \mathrm{L}$ of cell suspension using a Cytospin. Slides were stained with Wright and Giemsa dyes, air-dried, fixed with a drop of Permount (vwr) and then covered with a coverslip. Cell types were identified by characteristic morphologies under bright field microscopy at 400× magnification. 
Cell counts were performed randomly using several fields of view from each slide. Flow cytometry analysis of cell types was attempted on these NL samples, however the large cell size of nasal epithelial cells resulted in repeated clogging of the lines in the flow cytometer.

Target inflammatory biomarkers: Cytokine and chemokine analysis was performed according to our previously published method [5]. The first round of nasal lavage samples was assayed using a 42-plex high sensitivity human cytokine kit (Millipore, Billerica, MA), according to the manufacturer's instructions. The results were then analyzed using a Luminex 200 IS System (Luminex Corporation, Austin, TX). Cytokine concentrations were calculated, using Upstate Beadview (Temecula, CA) software. Following these preliminary results, up to 14 cytokines showing differences between copier operators and control groups were selected for routine analysis using a 14-plex kit from the same manufacturer. The 14 cytokines included Eotaxin, EGF, G-CSF, GM-CSF, IL-1 $\alpha$, IL-1 $\beta$, IL-6, IL-8, IL-10, Interferon- $\gamma$ (IFN- $\gamma)$, MCP-1, TNF- $\alpha$, Fractalkine, and VEGF. Cytokine levels in nasal lavage fluid were well above the Luminex limits of detection for most samples (which for most cytokines is in the low teens of $\mathrm{pg} / \mathrm{mL}$ ). Cytokines with values below their respective limit of detection (LOD) were estimated as $\mathrm{LOD} / \sqrt{ } 2$ for that particular cytokine.

Total protein: Total protein concentration was measured from the supernatant in all NL samples using a bicinchoninic acid (BCA) protein assay kit (Pierce, Rockford, USA) according to the manufacturer's instructions, with measurements performed using a 96-well microplate reader (SPECTRAmax+384, Molecular Devices). 
Urine Sample Collection: Urine samples were collected in sterile medical grade $90 \mathrm{~mL}$ containers, specifically designed for this purpose. After collection, the samples were centrifuged at $5000 \times g$ for $10 \mathrm{~min}$ at $4{ }^{\circ} \mathrm{C}$, aliquoted in several individual $1 \mathrm{~mL}$ polypropylene cryovials and stored at $-80{ }^{\circ} \mathrm{C}$ until use.

8-OH-dG oxidative stress biomarker analysis: Urine analysis for $8-O H-d G$ was done on an absorbance microplate reader using a commercially available ELISA kit (Japan Institute for the Control of Aging (JICA), Fukuroi, Japan). The assay was performed according to the manufacturer's instructions. The $8-O H-d G$ values from the samples were calculated based on calibration sigmoid plots of the absorbance $(450 \mathrm{~nm})$ of an $8-O H-d G$ standard at various concentrations. Urine samples, diluted 4-10 times, were analyzed for creatinine as previously described using a colorimetric assay kit based on picric acid (Oxford Biomedical Research Inc.) per manufacturer's instructions, and $8-O H-d G$ measurements were reported as creatinineadjusted concentrations (microgram/gram) to account for variations in urine dilution.

Statistical Analysis: Exposure and biomarker data were examined for the underlying distributions using the Shapiro-Wilks statistics and by graphing probability plots and histograms using the SAS System for the PC (SAS v 9.2 Inc., Carry, NC). Exposure data (e.g. total number concentration as measured by different instruments) fitted a log normal distribution. The natural logarithms of the measured exposure data were used for all analyses, and the geometric mean (GM) and geometric standard deviation (GSD) were used to describe such distributions. Realtime PM measurements were found to be highly auto-correlated and, as such, summary statistics were calculated using the AUTOREG procedure in SAS. Similarly, all biomarker data, except for inflammatory cells, were found to be log normally or approximately log normally distributed and all subsequent analyses were performed on log-transformed data. Inflammatory cell data, 
which were expressed as percent difference from controls, were normally distributed. The data (exposure and biomarker) below the limit of detection were estimated as $\mathrm{LOD} / \sqrt{ } 2$. Because of the repeated measurement design, mixed models with a random intercept and compound symmetry covariance structure were used to test for cross day and cross week changes in cytokines, total protein, and 8-OH-dG levels [5].

\section{RESULTS}

Study population: A total of 17 subjects ( 6 full time copier operators from three copy centers and 11 controls) were enrolled in the study. The demographics of subjects stratified by their job status are summarized in Table 1. The mean age of the participating copier operators, 43.0 years old (range 37-57), was slightly higher than the mean age of control subjects (39.3 year old (range 25-61). Of the 6 full time copier operators, only one was a smoker. All others (subjects and controls) were never smokers. The smoker was included in the final analysis because biomarker levels for this individual were not different from the other five. Furthermore, excluding this individual from the analysis set (five vs. six subjects) did not have a statistically significant impact on biomarker distribution values for the exposed group or its comparison with controls.

Some of the symptoms reported by the operators were headache, watery eyes, loss of smell, and dry mouth during working hours. One operator $($ Center $C)$ reported serious sinus problems that developed during the first two years of employment, and that required surgical intervention. $\mathrm{He}$ continued to have periods of a severe runny nose and allergic symptoms but was not taking any medications at the time of the study. One of the employees in center B stated that she was diagnosed with asthma. This person was taking over-the-counter oral medications to treat 
allergies during at least one week of the study period. All control individuals were healthy nonsmokers who did not report any respiratory symptoms.

Commercial copy centers: All three copy centers featured two high-volume, high-speed photocopiers from the same manufacturer, capable of monochrome print speeds between 75 and 105 pages per minute. Printing volume for each copy center varied by day. Center A had a daily average of 14,373 copies/day (range 5670 - 21674), center B 4500 (range 1053-12060); and center C 5258 (range 2100-8300).

Nanoparticle exposure: Detailed physico-chemical and morphological characterization of nanoparticle exposures, including size distribution, number concentration, and chemical analysis in these centers is published in Martin et al. [2] as part of a much larger study. The summary exposure information provided herein has been extracted from that study and is intended to provide relevant exposure information. The total particle number concentrations showed considerable variation from day to day and center to center and were found to be log normally distributed. The weekly geometric mean concentration as measured by FMPS ranged from $\sim 11,450$ to 13,600 particle/ $/ \mathrm{cm}^{3}$ (Table 2). The range of daily geometric means varied between 4300 and 30,800 particle/ $\mathrm{cm}^{3}$. Geometric standard deviations varied between 1.7 and 2.9. Peak maxima as high as 143,000 particles $/ \mathrm{cm}^{3}$ were recorded during the study weeks in these centers. Arithmetic mean exposures varied between 14640 and 21860 particle $/ \mathrm{cm}^{3}$. Average particle size distributions were stable throughout weekly measurements, with count median (electrical mobility) diameters of 23-28 nm (Figure 1). Mass size distribution data are shown in Supplemental Figure S1. The mass concentration in Center A was approximately 2 times the mass concentration found in Center B and Center C. Elemental composition data are presented in 
Table 3. Note that other than $\mathrm{Ca}, \mathrm{P}, \mathrm{S}, \mathrm{Na}$ and $\mathrm{K}$ (last two not shown), the more abundant elements were $\mathrm{Fe}, \mathrm{Zn}, \mathrm{Al}, \mathrm{Ti}$ and $\mathrm{Cu}$, each likely originating from their respective oxides.

Lung deposition dose: Lung deposition was estimated using the Multiple Particle Path Dosimetry Model software (MPPD v.2.1). The deposited fraction for each pulmonary region was estimated to be $\sim 6 \%(5.7-6.2 \%)$ in the head and upper airways region, $\sim 12 \%(11.2-13.1 \%)$ for the thoracic region, and $\sim 18 \%(17-20.2 \%)$ for the alveolar region (Table 4, Supplemental Figure S2). The total deposited fraction anywhere in the airways was estimated at $33.7-39.8 \%$.

\section{Inflammatory biomarkers in the nasal lavage:}

Inflammatory Cells: We calculated the content of Peripheral Mononuclear Cells (PMNs) as a percentage of total cells in each NL sample. The mean \% PMN in the NL of control subjects was $14.9 \%$ and there was no statistical difference between different time points across any given week (i.e. Mo-AM, Mo-PM and Fr-PM). However, the mean \% PMN in the NL of chronically exposed copier operators was much higher, constituting $39.9 \%$ of the total cells, which was significantly higher than controls. In addition, the PMN concentration remained high across the whole week for all weeks of analysis (Week 1, $38.73 \%$; Week 2, 42.18\%; Week 3, 42.25\%) in the chronically exposed copier operators and there was no significant difference between different days of the weeks as well as during different weeks (Tables 5 and 6 and Figures 2 and 3).

Total Protein: The geometric mean total protein in the NL of chronically exposed copier operators was four-fold higher $(1491.08 \mu \mathrm{g} / \mathrm{mL})$ as compared to controls $(341.24 \mu \mathrm{g} / \mathrm{mL})$ (Table 5). No significant difference was observed in the mean total protein values of the chronically 
exposed copier operators during the week (Mo-AM, $1495.09 \mu \mathrm{g} / \mathrm{mL}$; Mo-PM, $1497.94 \mu \mathrm{g} / \mathrm{mL}$; Fr-PM, $1480.27 \mu \mathrm{g} / \mathrm{mL}$ ) and between-weeks (Week 1, $1594.25 \mu \mathrm{g} / \mathrm{mL}$; Week 2, $1449.75 \mu \mathrm{g} / \mathrm{ml}$; Week 3, $1415.27 \mu \mathrm{g} / \mathrm{mL}$ ) (Table 6, Figure 3). Similarly, the mean total protein did not change significantly across weeks in control subjects.

Inflammatory Cytokines and Chemokines: Fourteen inflammatory cytokines and chemokines were assessed in the NL samples. Five of them, namely IL-6, IL-8, TNF $\alpha$, IL-1 $\beta(p<0.0001)$ and Eotaxin ( $\mathrm{p}<0.05)$, were found to be significantly elevated in the chronically exposed copier operators. The level of these five cytokines did not change significantly across days and weeks in the chronically exposed individuals (Tables 5 and 6 and Figure 3). The ratio of the geometric mean values (copier operators/ controls) ranged from 2 to 10, depending on the type of cytokine. For example, IL-6 in chronically exposed operators was elevated 9.4-fold relative to controls, IL8, 12.1-fold; TNF $\alpha, 6.0$-fold; IL-1 $\beta, 2.27$-fold; and Eotaxin, 2.4-fold. G-CSF was found to be significantly down-regulated $(\mathrm{p}<0.0001)$ in copier operators relative to controls; the geometric mean values for G-CSF in exposed workers was 10.5 -fold lower than in controls.

8-OH-dG in urine: The mean $8-O H-d G$ concentrations in chronically exposed copier operators $(19.05 \mu \mathrm{g} / \mathrm{g})$ was significantly higher than in controls $(6.80 \mu \mathrm{g} / \mathrm{g})$ (Tables 5 and 6). No significant difference was observed in $8-O H-d G$ concentration in different within-week samples (Mo-AM, $18.78 \mu \mathrm{g} / \mathrm{g}$; Mo-PM, $18.79 \mu \mathrm{g} / \mathrm{g}$; Fr-PM, $19.59 \mu \mathrm{g} / \mathrm{g}$ ) and between-weeks (Week 1, $17.26 \mu \mathrm{g} / \mathrm{g}$; Week 2, $20.60 \mu \mathrm{g} / \mathrm{g}$; Week 3, $19.83 \mu \mathrm{g} / \mathrm{g}$ ) in chronically exposed copier operators (Figure 3). Similarly, there was no significant difference in $8-O H-d G$ concentration across throughout the week or between weeks in the control group. 
Cross-week differences: There were no significant differences between Mo-AM and Mo-PM biomarker measurements as well as between Mo-PM and Fr-PM for all markers ( $\mathrm{p}>0.05)$ (Supplemental Figure S1), suggesting a steady state has been reached in these biomarkers.

\section{DISCUSSION}

In the present study, we report on the kinetics of upper airway inflammation and systemic oxidative stress in a small group of six copier operators from three copy centers following chronic exposure to nanoparticles from photocopiers. This study is the sixth in a series of reports published by the authors describing the physicochemical properties and toxicological potential of nanoparticles from photocopiers. In earlier studies, we reported significantly elevated levels of inflammatory and oxidative stress markers after acute exposure to such nanoparticles, and these results were corroborated by in-vitro data using several human cell lines as well as animal instillation studies [3-6]. We also show in-vitro [9] and in-vivo [7] that these nanoparticles were more toxic and inflammogenic than the corresponding fine particles fraction $(0.1-2.4 \mu \mathrm{m})$ and size-matched copper oxide nanoparticles and iron oxide nanoparticles, as well as welding fumes and diesel exhaust.

We purposefully designed the current study with the same matched molecular endpoints of upper airway inflammation and systemic oxidative stress as in the acute exposure study [5] so that changes in such biomarkers from acute to chronic exposures could be investigated. Furthermore, the repeated measures design over three random weeks allowed investigation of variability in these inflammatory and oxidative stress markers between days in a week and across different weeks. High variability (aka sensitivity) of such biomarkers to daily changes in exposure profiles 
limits their utility for routine, larger scale biomolecular studies.

One important observation relates to remodeling of inflammatory patterns in chronically exposed individual relative to a single acute exposure. PMN and total protein in nasal lavage and $8-\mathrm{OH}$ $d G$ in urine remained elevated in chronically exposed individuals, although at much higher levels than during a single acute exposure. Only a subset of five cytokines and chemokines were differentially expressed following chronic exposures. Four of them, namely IL-6, IL-8, TNF $\alpha$, and IL-1 $\beta$, were up-regulated, whereas G-CSF was down-regulated relative to controls. Two other cytokines, IL-1 $\alpha$ and Eotaxin, were slightly elevated with marginal significance. However, IL-10, a well know anti-inflammatory cytokine that was overexpressed in volunteers following a single acute exposure, was no longer elevated in chronically exposed individuals. As we will discuss in detail later in this section, this current observation suggests that the anti-inflammatory feedback loop involving IL-10 may have become exhausted and overridden by other cellular processes. The concentrations of these overexpressed cytokines and chemokines - IL-6, IL-8, TNF $\alpha$, and IL-1 - were 5-10 times higher in the copier operators as compared to healthy subjects after a single acute exposure in our earlier study. In contrast, G-CSF, which was overexpressed $\sim 10$ times following an acute exposure, was now down-regulated by an order of magnitude in chronically exposed individuals.

Inflammation is a vital biological response that has evolved to deal with cell injury by stimulating repair of damaged tissue and regeneration of healthy tissue [18-20]. However, when it occurs in excess or in particularly sensitive tissues (airways, for example), inflammation is harmful because it creates and sustains the molecular pathway/s involved in the development of a variety of chronic diseases, including chronic obstructive pulmonary disease (COPD), cardiovascular diseases, asthma and cancer [21-25]. The overall picture from this analysis, 
although limited to six individuals, supports the conclusion that photocopier operators in the present study are under a state of sustained chronic upper airway inflammation and chronic oxidative stress (as supported by the urine $8-O H-d G$ data). This is concerning because chronic inflammation is a common denominator in numerous chronic diseases, including airway hyperresponsiveness and asthma.

The up-regulated pro-inflammatory cytokines (IL-8, IL-6, TNF $\alpha$ and IL-1 $\beta$ ) are known to play a key role in orchestrating chronic inflammation by recruiting, activating, and promoting the survival of multiple inflammatory cells in the respiratory tract. They are also known to be elevated in rhinitis, asthma, COPD and lung cancer. G-CSF, which was significantly underexpressed in chronic individuals, is a central regulator of granulopoiesis during inflammatory responses. G-CSF is a pleiotropic cytokine best known for its role in promoting the production and function of neutrophils, and this is consistent with their abundance (up to $40 \%$ of total cells) in the nasal lavage. A possible explanation for the G-CSF down-regulation may be establishment of a negative feed back loop on respiratory cells in response to excessive chronic inflammation.

Our observations are consistent with gene expression data generated from earlier studies. For example, we have already reported that in-vitro exposure of THP-1 macrophages to NPs collected from one photocopy center (A in Table 2) induced up-regulation of the genes encoding $\mathrm{TNF} \alpha$ inflammatory proteins, those encoding oxidative stress proteins (e.g. HO1) and p53, and genes encoding known regulators of apoptosis including CASP8 [5]. Furthermore, Pirela et al. [8] also documented oxidative stress in THP-1 macrophages and small airway bronchial cells following exposure to printer-emitted particles. 
Lucas and Maes [26] describe two clusters of commonly reported symptoms associated with nanoparticle exposures to hard copy devices: (i) airway hyperresponsiveness and hyperreactivity, and (ii) chronic fatigue (syndrome). Airway hyperresponsiveness and hyperreactivity symptoms manifest as irritation, upper and lower airway hyperresponsiveness, nose and throat discomfort, burning tongue, chronic rhinitis, cough, plus irritation of the larynx and vocal cords. Asthma, these authors further state, may develop in a subset of susceptible individuals, which with continued exposure may progress towards a generalizable, non-specific asthma. Chronic fatigue is manifested as general weakness, lack of energy and exhaustion, headaches, dizziness, reduced concentration, sleep disorders, depressive moods, gastro-intestinal tract symptoms similar to irritable bowl syndrome, and pinprick sensations on the skin.

Limited case studies further support the above cluster of symptoms. For example, Zina et al. [27] presented a medical case history of a casual photocopier operator developing skin rashes on arms, neck, head and upper trunk, which were linked to use of the copier. D'Alessandro et al. [28] presented another case report of a 40-yr old female clerical worker with a chronic cough induced by printer emissions. In this later study, the patient was kept exposure- and symptom free for four weeks prior to being asked to operate the printer for one hour. Medical evaluations and pulmonary function tests, including fiber optic bronchoscopy, bronchoalveolar lavage (BAL), and bronchial provocation with metacholine, were performed four weeks pre-exposure (when the patient was symptom free), immediately and $48 \mathrm{hr}$ post-exposure. The authors found infiltration of neutrophils and lymphocytes in BAL $48 \mathrm{hr}$ post-exposure, as well as moderate inflammation of the bronchial mucosa and infiltration of lymphocytes along with a few plasma cells. All other tests, including the CD4/CD8 ratio, were normal. The authors concluded that this short one hour exposure to laser printer emissions induced cough consistent with an acute 
inflammatory response. Overall, our findings from this pilot study agree with the above mentioned reports.

Owing to a much smaller surface area $\left(\sim 150 \mathrm{~cm}^{2}\right)$ compared to lower airways $\left(\sim 140 \mathrm{~m}^{2}\right)$, the nose and upper airways may receive over 2000x times higher tissue doses per unit surface area than the deep lungs. For a typical nanoparticle size distribution generated by hardcopy devices (median of $35-40 \mathrm{~nm}$ and geometric standard deviation of 1.5 ), about $6-8 \%$ of nanoparticles deposit in the nose and upper airways, compared to $\sim 15-20 \%$ in the lower airways (Table 4). Therefore, the high nanoparticle dose to the upper airways and olfactory bulbs may well be implicated in the development of anosmia and hyposmia, as well as airway hyperresponsiveness and hypersensitivity, chronic fatigue and other symptoms involving nervous system response, as described by Lucas and Maes [29] and D’Alessandro et al. [28].

We are mindful that this is a small size study involving a limited number of 6 copier operators and 11 controls, and care should be taken not to over interpret the current findings. Alternative explanations, including factors other than nanoparticles, can be offered for human studies. For example, our exposed group was slightly older than controls, and this may influence differences in biomolecular responses between the two groups. The selection criteria among the controls were rather tight, and this also may have helped enhance the observed differences in expressed biomarkers. Other causative agents (unknown to us) may be involved. It is, however, striking to see such clear-cut differences between copier employees and controls for such small group sizes. Furthermore, the consistency of findings across different testing platforms (cells, animals, acute exposures in humans, and this study on chronic exposures) as reviewed in detail in [30], points to nanoparticles from photocopiers as a likely cause, and raises legitimate questions concerning upper and lower respiratory system health, immune responses, and possibly asthma. 
Recently, Karimi et al [31] reported significantly higher cough (odds ratio OR of 2.6), higher wheezing (OR 3), and reduced lung function capacity (FEV1 and FVC), in 150 copier operators relative to 114 controls in Iran. Of note, this study lacked any quantitative exposure information or exposure histories. Elango et al [32] also reported significantly higher prevalence of nasal blockage, cough, excessive sputum production, and breathing difficulties in copier operators relative to controls in a cohort of copier operators in India, as well as elevated oxidative stress markers in serum, including higher TBARS, lower Ferric Reducing Antioxidant Capacity of Serum (FRAC), higher plasma ICAM, IL-8, and leukotriene B4 (LTB 4$)$. Although this study measured numerous environmental pollutants, it did not measure exposures to copier emitted nanoparticles. Lastly, Yang et al [33] investigated the prevalence of chronic respiratory symptoms and acute irritative symptoms among 74 photocopy workers (exposure group) and 69 controls (employees of optical stores) in Taiwan. Authors reported higher, but not statistically significant, rates of chronic cough (adjusted OR 2.9), wheezing (adjusted OR 1.9), chronic bronchitis (adjusted OR 2.2), and dyspnea (3.1), for workers in copy centers relative to controls. Of note, this study lacked exposure information and the focus was on VOCs as the trigger agent, rather than nanoparticles. Large-scale molecular and epidemiological studies with strong quantitative exposure assessment are still lacking in copier operators and needed to establish quantitative exposure- respiratory response relationships.

Mechanistic insights: Possible molecular mechanisms. Lucas and Maes [26, 29] have put forth a general hypothesis that describes the underlying mechanisms that sustain systemic inflammation from copier-emitted and other nanoparticles. At the center of this particular hypothesis is a sustained radical cycle that starts with induction of damage associated molecular patterns (DAMP) due to nanoparticles, activation of other innate immune signaling pathways, and the 
production of pro-inflammatory molecules plus reactive oxygen and nitrogen species. As depicted in Figure 4, we hypothesize that nanoparticles released from photocopiers may induce a plethora of signaling cascades in the resident cells at tissue sites or in infiltrating inflammatory cells such as macrophages, neutrophils or dendritic cells. This may lead to the production of proinflammatory molecules, reactive oxygen and nitrogen species, which together bring about the tissue damaging response. The tissue damage caused by such nanoparticles can be affected in a number of ways. For example, nanoparticles could potentially cause direct injuries to tissues and thereby lead to the production of DAMPs, such as HMBG1, nucleic acids, or the metabolites and byproducts of purine nucleotides. DAMPs are then sensed by host toll receptors $(2,5,6$, etc. $)$ or other sensing receptors eventually leading to production of pro-inflammatory molecules. Nanoparticles may also directly trigger innate immune receptors. Whether such recognitions occur at the cell surface or in the subcellular organelles, such as endosomes, would dictate the type of immunological responses that are induced. Major players involved in such recognition are surface expressed or endosomal residing toll like receptors (TLR 2, 4, 5, and 6; or TLR 3, 7, 8 and 9, respectively), nod like receptors (NLRs), Rig I like receptors, etc. [34]. Because phagocytic cells take up these nanoparticles, it is conceivable that those innate immune receptors present either in the endosomes or in the cytoplasm become activated by their interaction with internalized nanoparticles.

Moreover, under environmental conditions, these nanoparticles may also carry on their surfaces some microbial-derived products, such as endotoxins, that are considered as potent stimuli for an inflammatory response. Of note, endotoxins in very small concentrations can provide ample stimulation through TLR4 leading to the production of pro-inflammatory cytokines, such as IL-6, TNF- $\alpha$, IL-8, etc. Innate immune cells, particularly neutrophils and macrophages, are recruited 
to the tissue sites during an inflammatory response and produce abundant reactive species (oxygen and nitrogen), thereby further enhancing an inflammatory circuitry and establishing a chronic inflammatory state. Indeed, some of the cytokines, such as IL-6, TNF-alpha and IL-8, were highly up regulated in the nasal lavage of photocopy center workers in our study suggesting, activation of such innate immune signaling pathways [5]. It is important to note, however, that we have previously shown [6] that copier nanoparticles themselves, independent of endotoxins, can activate innate immune signaling pathways. The identity of nanoparticlereceptor recognition patterns, i.e. what specific receptor recognizes which nanoparticle, needs to be investigated and will be pursued in future studies.

Furthermore, recent studies have documented that nanoparticles can directly stimulate cytosolic innate immune receptors, such as NLRs, with a subsequent activation of the inflammasome

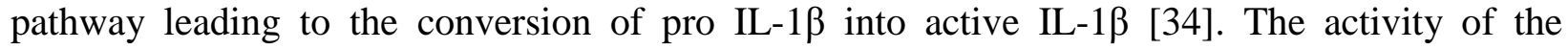
inflammasome pathway may also induce cell death by a phenomenon known as pyroptosis, which further aggravates the inflammatory cascade. In our previous studies we have observed cell death in THP-1 macrophages and epithelial cells exposed to copier emitted nanoparticles [6]. Studies that utilize animals with knocked out expression of single or multiple receptor molecules, as well as adaptor molecules required for inducing signaling and the production of inflammatory response, may prove necessary in order to further elucidate the exact molecular pathways and receptors involved. Potential candidates include Myd88 knockout mice or with non-functional inflammasome, to provide mechanistic insights into the causation of inflammation as a result of nanoparticle exposures from hard copy devices. Such mechanistic insights may open up new windows of therapeutic opportunities for treatment of airways responses in sensitive individuals. 


\section{CONCLUSION}

Chronic upper airway inflammation and systemic oxidative stress were documented in a small group of photocopier operators chronically exposed to nanoparticles. These findings are in concordance with the recent toxicological literature on printer-emitted particles and medical case reports, and therefore call for larger scale studies on the health effects of this population of photocopier operators. Sustained inflammation in the upper airways (IL-8, IL-6, TNF $\alpha$, IL-1 $\beta$, PMN, and total protein) and oxidative stress in urine $(8-O H d G)$ point to a sustained radical cycle that we hypothesize it may likely involve damaged biomolecules as a result of reactive oxygen species (ROS), activation of toll-like receptors, particularly TLR4, in nasal epithelial cells, and activation of the Nf-kB pathway in inflammation. While some elements of this radical cycle are supported with direct experimental evidence, future studies should address them directly in-vivo and in-vitro using knock-out mice or engineered cells lacking critical receptors or signaling molecules. Limited evidence from two of the six exposed subjects points to possible upper airway allergies, loss of smell and quality of life issues, and possible asthma. Such observations should be verified and validated with larger scale studies on possible health effects of copier emitted nanoparticles in the respiratory system and other organs [30].

\section{List of Abbreviations:}

1. Iron oxide $\left(\mathrm{Fe}_{2} \mathrm{O}_{3}\right)$

2. Titanium dioxide $\left(\mathrm{TiO}_{2}\right)$

3. Silicon dioxide $\left(\mathrm{SiO}_{2}\right)$

4. Aluminum oxide $\left(\mathrm{Al}_{2} \mathrm{O}_{3}\right)$

5. Cerium oxide $\left(\mathrm{CeO}_{2}\right)$

6. Copper $(\mathrm{Cu})$

7. Manganese (Mn)

8. Nickel (Ni) 
9. Epidermal Growth Factor (EGF),

10. Granulocyte-Colony Stimulating Factor (G-CSF), Granulocyte

11. Macrophage- Colony Stimulating Factor (GM-CSF),

12. Interlukin-(IL)

13. Monocyte Chemoattractant Protein-1 (MCP-1),

14. Tumor Necrosis Factor $\alpha$ (TNF- $\alpha)$,

15. Vascular Endothelial Growth Factor (VEGF).

16. 8-hydroxy-2'-deoxyguanosine (8-OH dG)

17. Small airway epithelial cells (SAEC)

18. Phosphate Buffered Saline (PBS)

19. Bovine Serum Albumin (BSA)

20. Limit of Detection (LOD)

21. Polymorphonuclear cells (PMNs)

22. Fast Mobility Particle Sizer (FMPS)

23. Aerodynamic Particle Sizer (APS)

24. Condensation Particle Counter (CPC)

25. Volatile organic compounds (VOCs)

26. Multiple Particle Path Dosimetry Model (MPPD)

27. Nasal Lavage (NL)

28. Bronchoalvelar Lavage (BAL)

29. Thiobarbituric acid reactive substances (TBARS)

30. Ferric Reducing Antioxidant Capacity of Serum (FRAC)

31. Damage associated molecular patterns (DAMP)

32. Toll like receptor (TLR)

33. Nod like receptor (NLR)

34. Reactive oxygen species (ROS)

35. Interferon- $\gamma(\mathrm{IFN}-\gamma)$

Ethical approval and consent to participate: The study was approved by the institutional review board of the University of Massachusetts Lowell (IRB Protocol \#: 09-117-BEL-XPD). Informed consent was taken from the participants.

Consent for publication: Not applicable

Availability of data and materials: The datasets generated during and/or analyzed during the current study will be available from the corresponding author on reasonable request. 
Funding: The study was funded in part through the National Science Foundation as a Nanoscale

Science and Engineering Centers Program (Award \# NSF-0425826), Grant No. 2 T42OH008416-09 from the National Institute for Occupational Safety and Health (NIOSH), and a seed grant from the UMass Lowell's Vice-Provost's office of research. Its contents are solely the responsibility of the authors and do not necessarily represent the official views of NIOSH.

Acknowledgments: The authors wish to sincerely thank the employees, managers and owners of each copy center for their generous support of this study. We thank Dr. Sharvan Sehrawat of IISER Mohali for his insights on interpretation of immunological responses as well as Prof. Vince Castranova for his critical review of the manuscript.

\section{REFERENCES}

1. Bello D, Martin J, Santeufemio C, Sun Q, Lee B K, Shafer M, Demokritou P:

Physicochemical and morphological characterization of nanoparticles from photocopiers: implications for environmental health. Nanotoxicology 2013, 7(5): 9891003.

2. Martin J, Bello D, Bunker K, Shafer M, Christiani D, Woskie S, Demokritou P: Occupational exposure to nanoparticles at commercial photocopy centers. $J$ Hazard Mater 2015, 298:351-360.

3. Pirela SV, Pyrgiotakis G, Bello D, Thomas T, Castranova V, Demokritou P: Development and characterization of an exposure platform suitable for physico-chemical, 
morphological and toxicological characterization of printer-emitted particles (PEPs). Inhal Toxicol 2014, 26(7):400-408.

4. Martin J, Demokritou P, Woskie S, Bello D. 2016. Indoor Air Quality in Photocopy Centers, Nanoparticle Exposures at Photocopy Workstations, and the Need for Exposure Controls. Annals of Occupational Hygiene. Accepted.

5. Khatri M, Bello D, Gaines P, Martin J, Pal AK, Gore R, Woskie S: Nanoparticles from photocopiers induce oxidative stress and upper respiratory tract inflammation in healthy volunteers. Nanotoxicology 2013, 7(5):1014-1027.

6. Khatri M, Bello D, Pal AK, Cohen JM, Woskie S, Gassert T, Lan J, Gu AZ, Demokritou P, Gaines P: Evaluation of cytotoxic, genotoxic and inflammatory responses of nanoparticles from photocopiers in three human cell lines. Part Fibre Toxicol 2013, 10:42.

7. Pirela S, Molina R, Watson C, Cohen JM, Bello D, Demokritou P, Brain J: Effects of copy center particles on the lungs: a toxicological characterization using a Balb/c mouse model. Inhal Toxicol 2013, 25(9):498-508.

8. Pirela SV, Miousse IR, Lu X, Castranova V, Thomas T, Qian Y, Bello D, Kobzik L, Koturbash I, Demokritou P: Effects of Laser Printer-Emitted Engineered Nanoparticles on Cytotoxicity, Chemokine Expression, Reactive Oxygen Species, DNA Methylation, and DNA Damage: A Comprehensive in Vitro Analysis in Human Small Airway Epithelial Cells, Macrophages, and Lymphoblasts. Environ Health Perspect 2016, 124(2):210-219. 
9. Khatri M, Bello D, Pal AK, Woskie S, Gassert TH, Demokritou P, Gaines P: Toxicological effects of PM0.25-2.0 particles collected from a photocopy center in three human cell lines. Inhal Toxicol 2013, 25(11):621-632.

10. Liou SH, Tsai CS, Pelclova D, Schubauer-Berigan MK, Schulte PA: Assessing the first wave of epidemiological studies of nanomaterial workers. J Nanopart Res 2015, 17:413.

11. Liou SH TT, Wang SL, Li LA, Chiang HC, Li WF, Lin PP, Lai CH, Lee HL, Lin MH, Hsu JH, Chen CR, Shih TS, Liao HY, Chung YT: Epidemiological study of health hazards among workers handling engineered nanomaterials. J Nanopart Res 2012, 14:878-892.

12. Wagener AH, Zwinderman AH, Luiten S, Fokkens W, Bel EH, Sterk PJ, Drunen CM: The Impact of Allergic Rhinitis and Asthma on Human Nasal and Bronchial Epithelial Gene Expression. Plos One 2013, 8(11):e80257.

13. Vroling AB, Jonker MJ, Luiten S, Breit TM, Fokkens WJ, van Drunen CM: Primary nasal epithelium exposed to house dust mite extract shows activated expression in allergic individuals. Am J Respir Cell Mol Biol 2008, 38(3):293-299.

14. Bernstein JA, Alexis N, Bacchus H, Bernstein IL, Fritz P, Horner E, Li N, Mason S, Nel A, Oullette $\mathrm{J}$ et al: The health effects of non-industrial indoor air pollution. J Allergy Clin Immunol 2008, 121(3):585-591.

15. Bernstein JA, Smith A: Physiology and host immune responses of the nose and sinuses. In: Diseases of the Sinuses: A Comprehensive Textbook of Diagnosis and Treatment. Edited by Christopher C. Chang GAI, M. Eric Gershwin. New York: Springer; 2014: 4556.

16. Kowalska M, Zajusz-Zubek E: Occupational exposure to ozone in workers using photocopiers and printers. Medycyna pracy 2009, 61:549-551. 
17. Lee SC, S L, H KF: Characterization of VOCs, ozone, and PM10 emissions from office equipment in an environmental chamber. Buildings and Environment 2001, 36(7):837842 .

18. Rock KL, Latz E, Ontiveros F, Kono H: The Sterile Inflammatory Response. Anl Rev Immunol 2009, 28:321-342.

19. Tracey KJ: The inflammatory reflex. Nature 2002, 420: 853-859.

20. Stanley AC, Lacy P: Pathways for cytokine secretion. Physiology 2010, 25:218-229.

21. Monteseirin J: Neutrophils and asthma. J Investig Allergol Clin Immunol 2009, 19(5):340-354.

22. Garvey C: Recent updates in chronic obstructive pulmonary disease. Postgrad Med 2016, 128(2):231-238.

23. Vijayan VK: Chronic obstructive pulmonary disease. Indian J Med Res 2013,137(2):251-269.

24. Laveti D, Kumar M, Hemalatha R, Sistla R, Naidu VG, Talla V, Verma V, Kaur N, Nagpal R: Anti-inflammatory treatments for chronic diseases: a review. Inflamm Allergy Drug Targets 2013,12(5):349-361.

25. Elinav E, Nowarski R, Thaiss CA, Hu B, Jin C, Flavell RA: Inflammation-induced cancer: crosstalk between tumours, immune cells and microorganisms. Nat Rev Cancer 2013,13:759-771.

26. Lucas K, Maes M: Role of the Toll Like receptor (TLR) radical cycle in chronic inflammation: possible treatments targeting the TLR4 pathway. Mol Neurobiol 2013, 48(1):190-204. 
27. Zina AM FE, Bundino S: Allergic contact dermatitis from formaldehyde and quaternium-15 in photocopier toner. Contact Dermatitis 2000, 43(4):241-242.

28. D'Alessandro A, Waldburg N, Boeckelmann I, Schreiber J: Coughing from Copiers? Workplace Induced Chronic Cough after Exposure to Laser Printer Exhaust. $J$ Allergy Ther 2013, 4:154. doi: 10.4172/2155-6121.1000154.

29. Lucas K, Maes M: Molecular mechanisms underpinning laser printer and photocopier induced symptoms, including chronic fatigue syndrome and respiratory tract hyperresponsiveness: pharmacological treatment with cinnamon and hydrogen. Neuro Endocrinol Lett 2013, 34(8):723-737.

30. Pirela S, Martin J, Bello D, Demokritou P: Nanoparticle exposures from nano-enabled toner-based printing equipment and human health: State of science and future research needs. Critical reviews in toxicology, undergoing revisions.

31. Karimi A, Slamizad S, Mostafaee M, Momeni Z, Ziafati F, Mohammadi S: Restrictive Pattern of Pulmonary Symptoms among Photocopy and Printing Workers: A Retrospective Cohort Study. J Res Health Sci. 2016, 16(2):81-84.

32. Elango N, Kasi V, Vembhu B, Poornima JG: Chronic exposure to emissions from photocopiers in copy shops causes oxidative stress and systematic inflammation among photocopier operators in India. Environ Health, 2013, 12(1): p. 78.

33. Yang C-Y, Haung YC: A Cross-Sectional Study of Respiratory and Irritant Health Symptoms in Photocopier Workers in Taiwan. Journal of Toxicology and Environmental Health, Part A, 2008, 71(19): p. 1314-1317.

34. Latz E, Xiao TS, Stutz A: Activation and regulation of the inflammasomes. Nat Rev Immunol 2013, 13(6):10-1038/nri3452. 


\section{Figure Legends:}

Figure 1. Average weekly size distribution of airborne nanoparticles emitted from photocopiers at three commercial photocopy shops (Center A, B and C) in the Northeast. The blue line indicates the arithmetic mean of each channel, whereas the dotted lines indicate the $5^{\text {th }}$ (light green) and the $95^{\text {th }}$ percentiles (red). Size distributions vary significantly between the different photocopy centers, but within each center they remain relatively stable across different days. CMD, Count median diameter, $\mathrm{nm} ; \sigma_{\mathrm{g}}$, geometric standard deviation of the average size distribution.

Figure 2. Illustration of neutrophils (PMN) in the nasal lavage of chronically exposed workers relative to controls. A. Illustrative optical microscopy images of the slides processed to stain neutrophils and nasal epithelial cells as described in the methods section. B. Crossweek differences in PMN of chronically exposed vs. controls in NL. Similar patterns were observed for several cytokines / chemokines and $8-O H-d G$ in urine. (MM, Monday morning; ME, Monday evening; FE, Friday evening refer to times of human biological sampling.)

Figure 3. Cross-week changes of PMN percentages and select biomarkers, namely total protein, IL-6, IL-8, TNF $\alpha$, IL-1 $\beta$, G-CSF, IL-10, and 8-OH-dG, in chronically exposed workers relative to controls. The Y-axis is $\ln$ (variable), except for PMN (\%,). All analyses were from NL, except for levels of $8-O H-d G$ that were determined in urine.

Figure 4. A proposed mechanism of copier and printer emitted nanoparticle-induced toxicity potentially involving multiple receptors, including surface expressed TLRs (e.g. TLR 4), endosomal residing TLRs (e.g. TLR 3, 7, 8 and 9) and Nod-like receptors (NLRs), leading to inflammasome and caspase activation, as well as NFkB and possible MAPK signaling. The mixed chemical exposure nature of these nanoparticles may involve additional molecular pathways. 

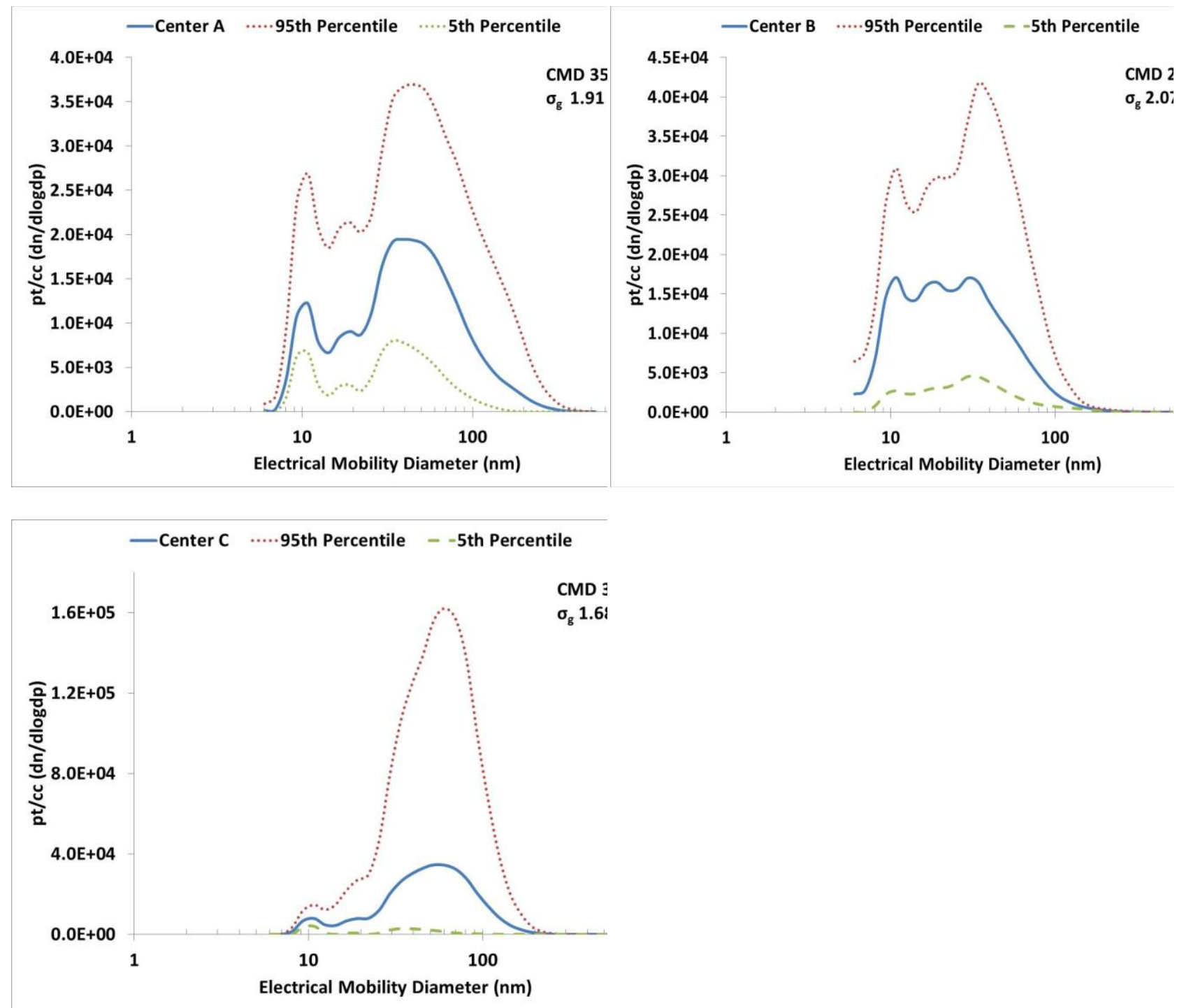

Figure 1 
Figure 2

A.
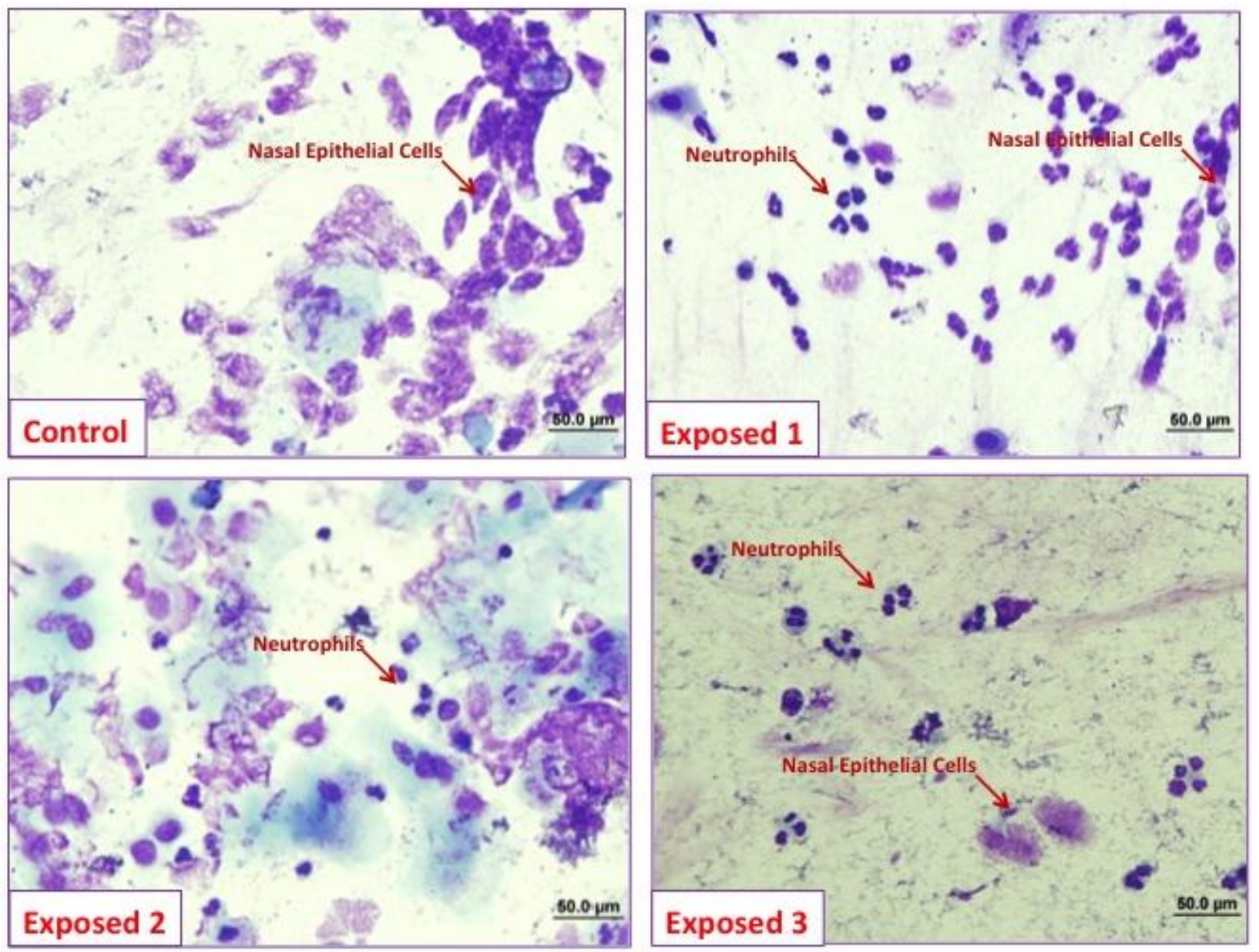

B. 


\section{Control}

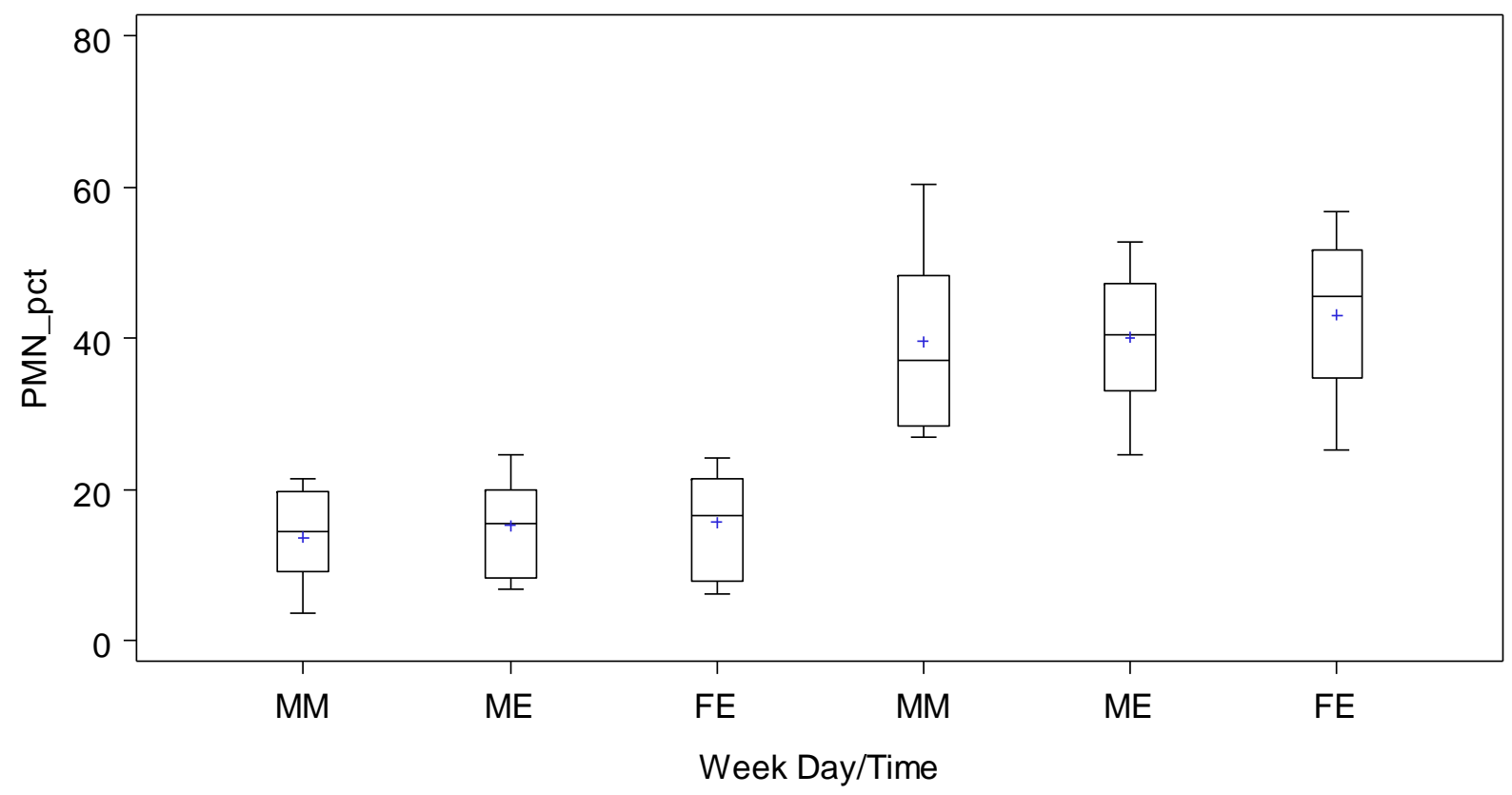


Figure 3

a. PMN (\% of total cell count in $\mathrm{NL}$ )

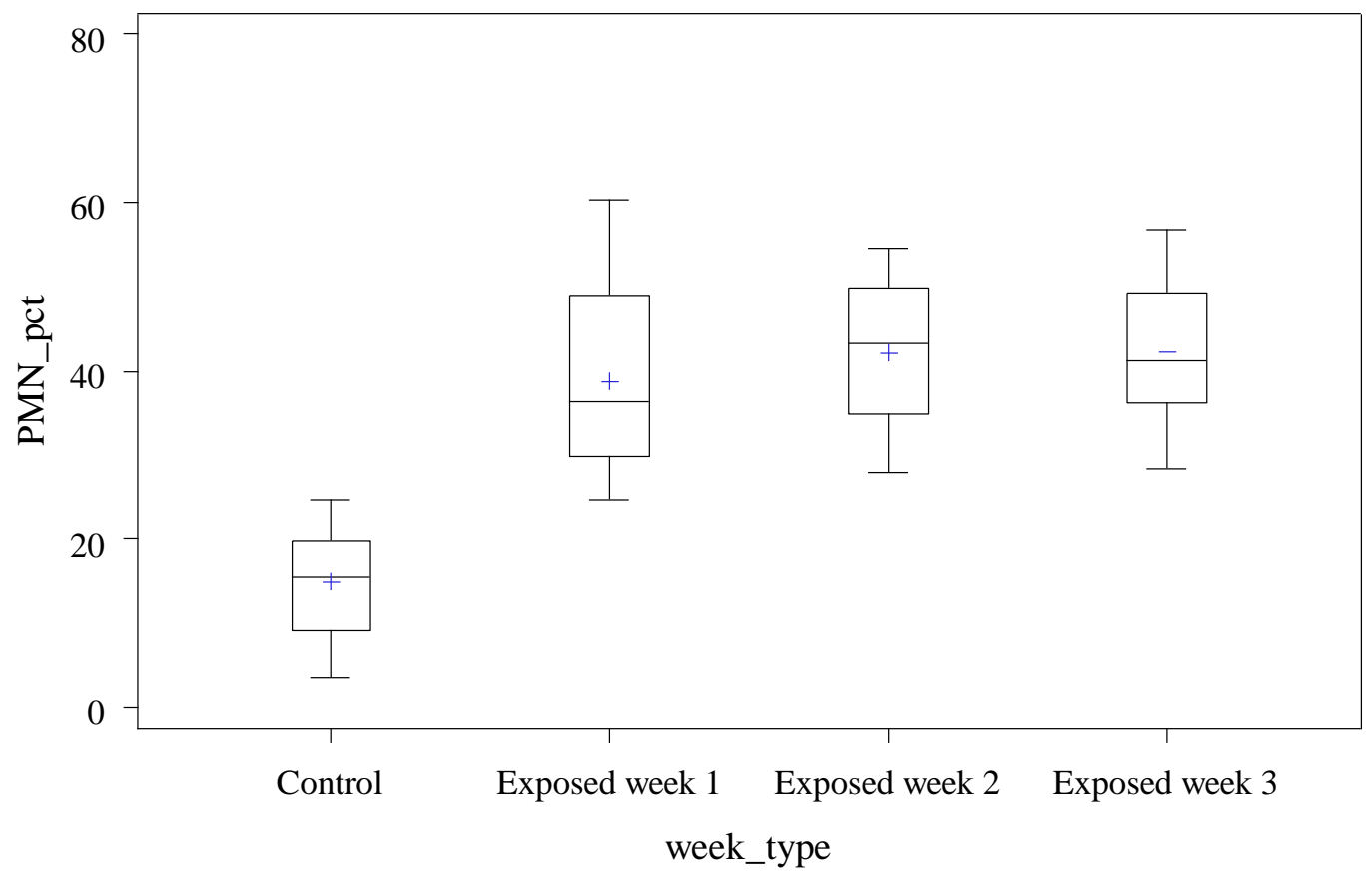

b. Total protein 


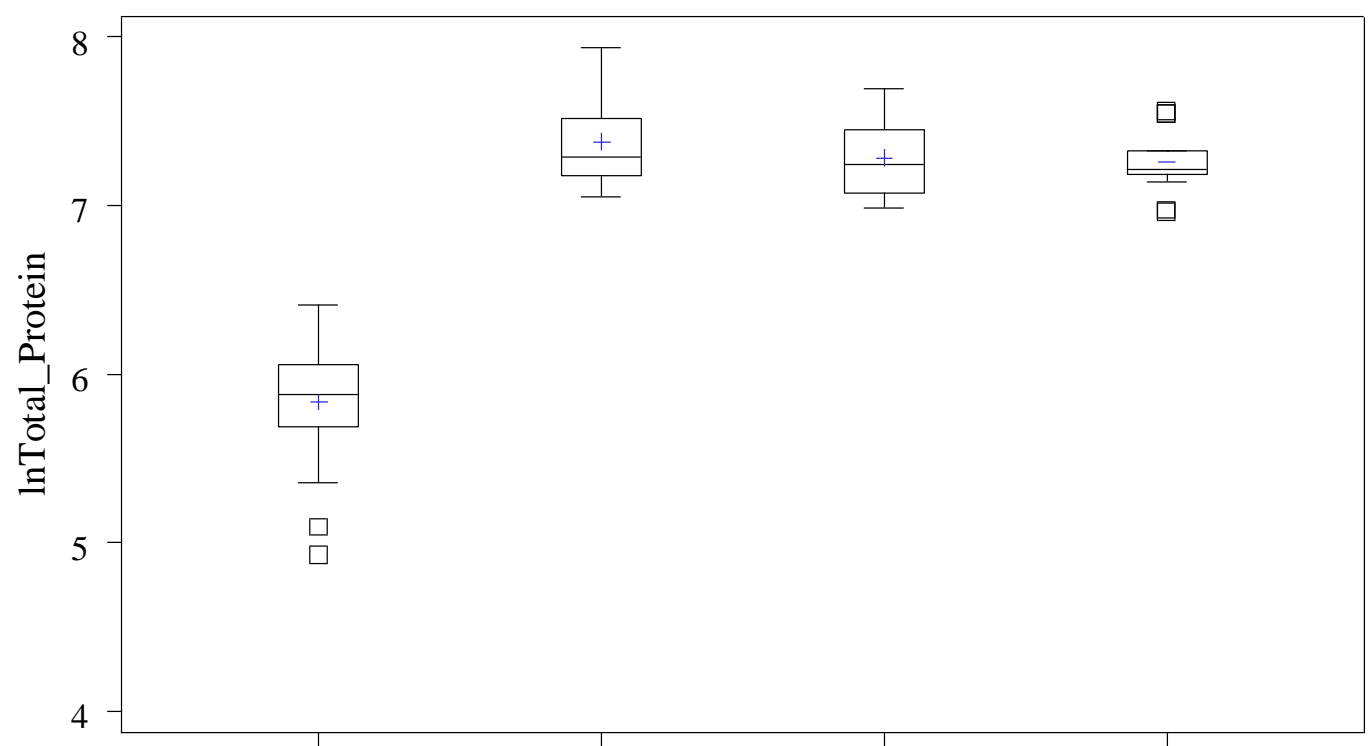

$\begin{array}{llll}\text { Control } & \text { Exposed week } 1 \quad \text { Exposed week } 2 \text { Exposed week } 3\end{array}$ week_type 
C. IL-6

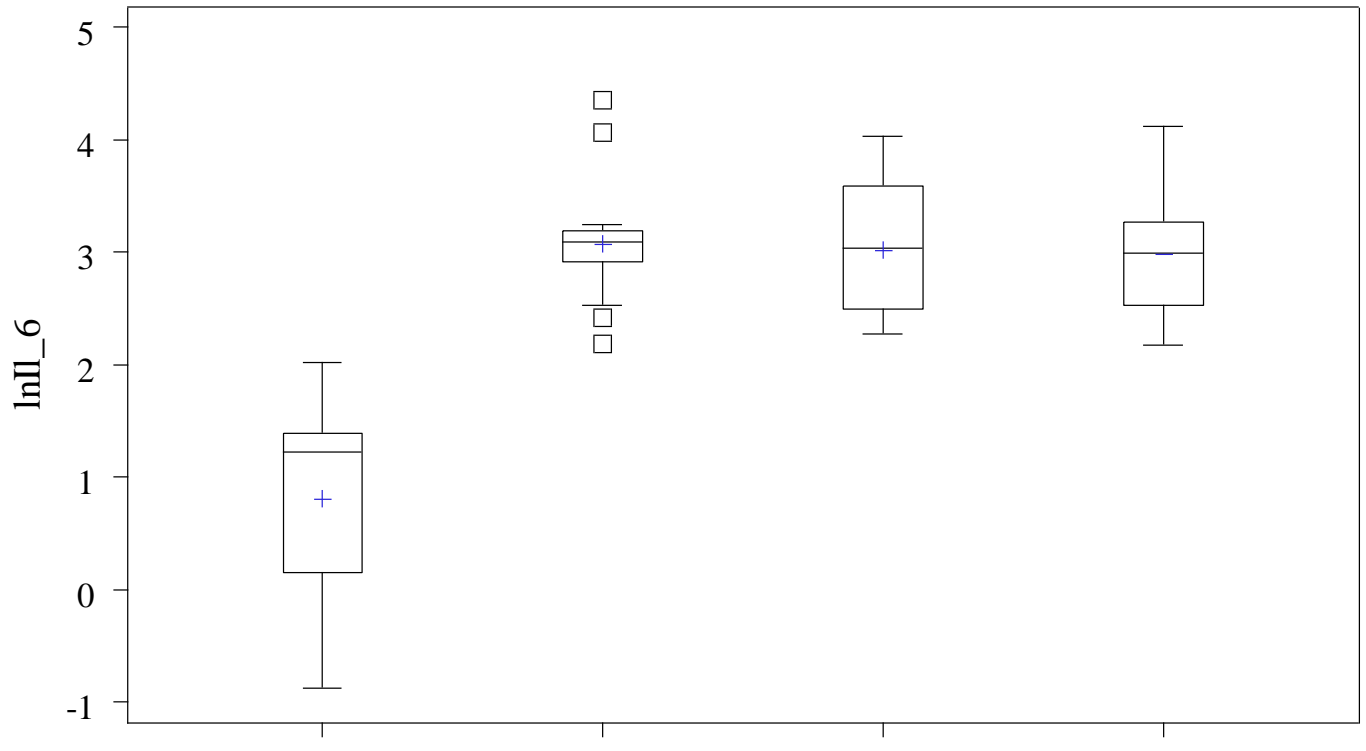

Control $\quad$ Exposed week $1 \quad$ Exposed week 2 Exposed week 3

week_type

d. IL-8

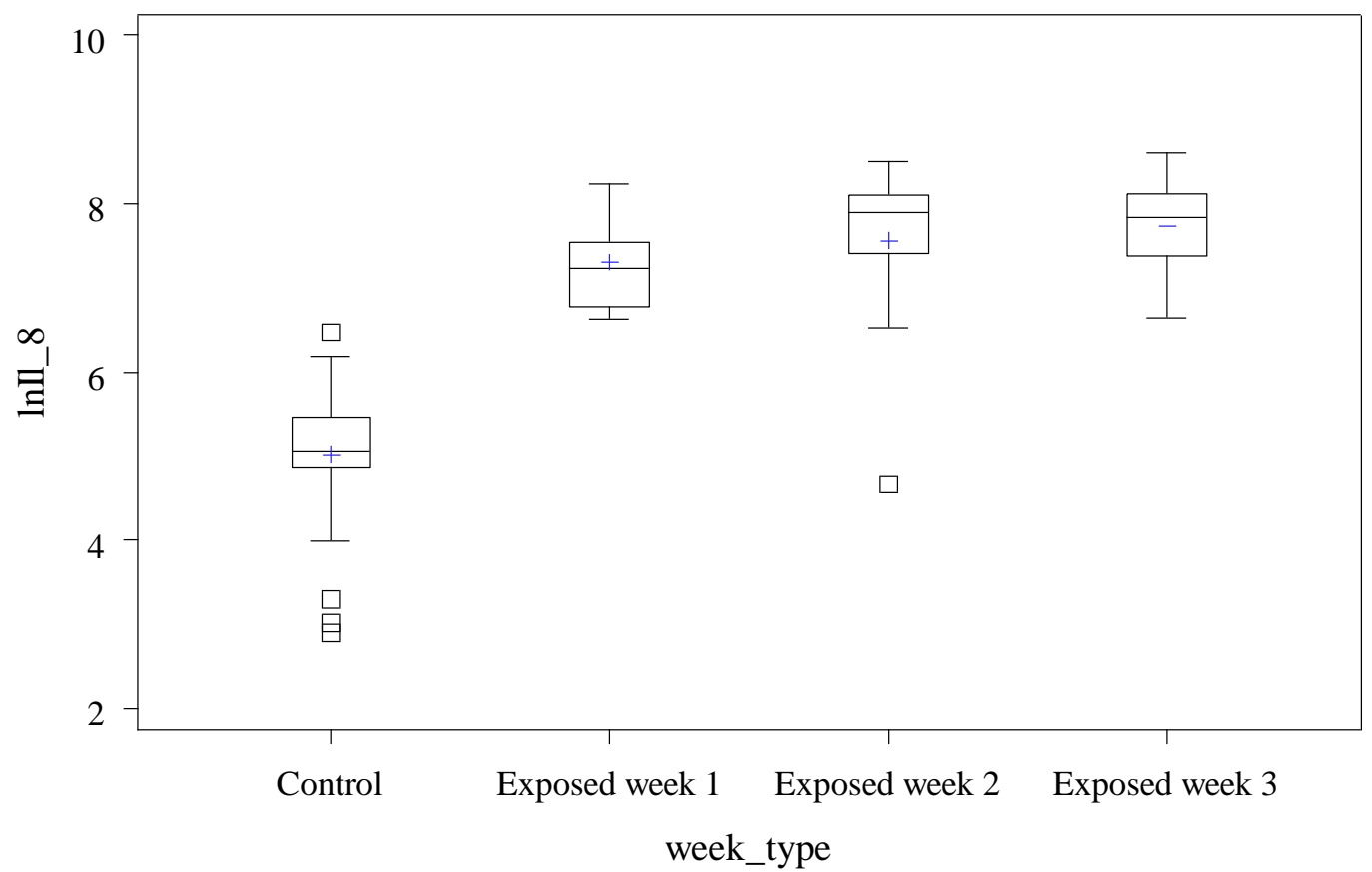


e. TNF- $\alpha$

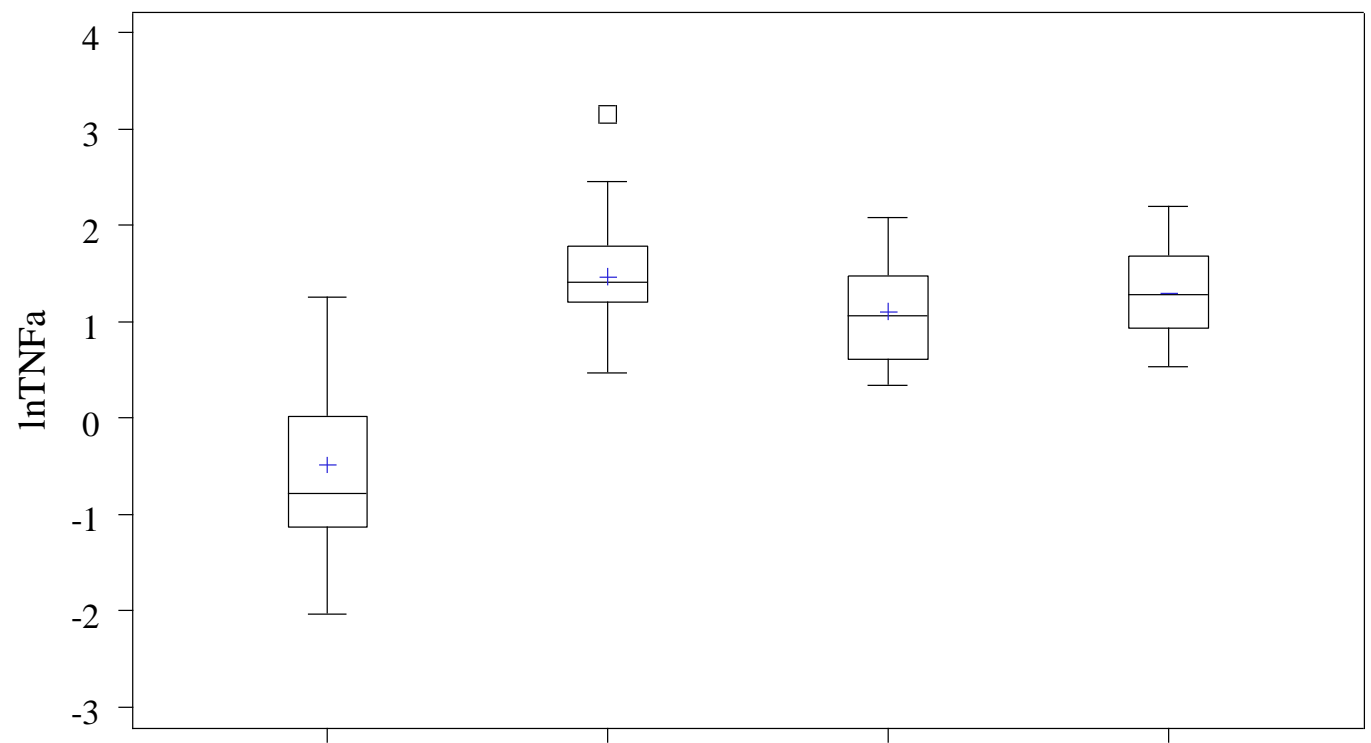

Control $\quad$ Exposed week $1 \quad$ Exposed week 2 Exposed week 3

week_type

f. IL-1及 


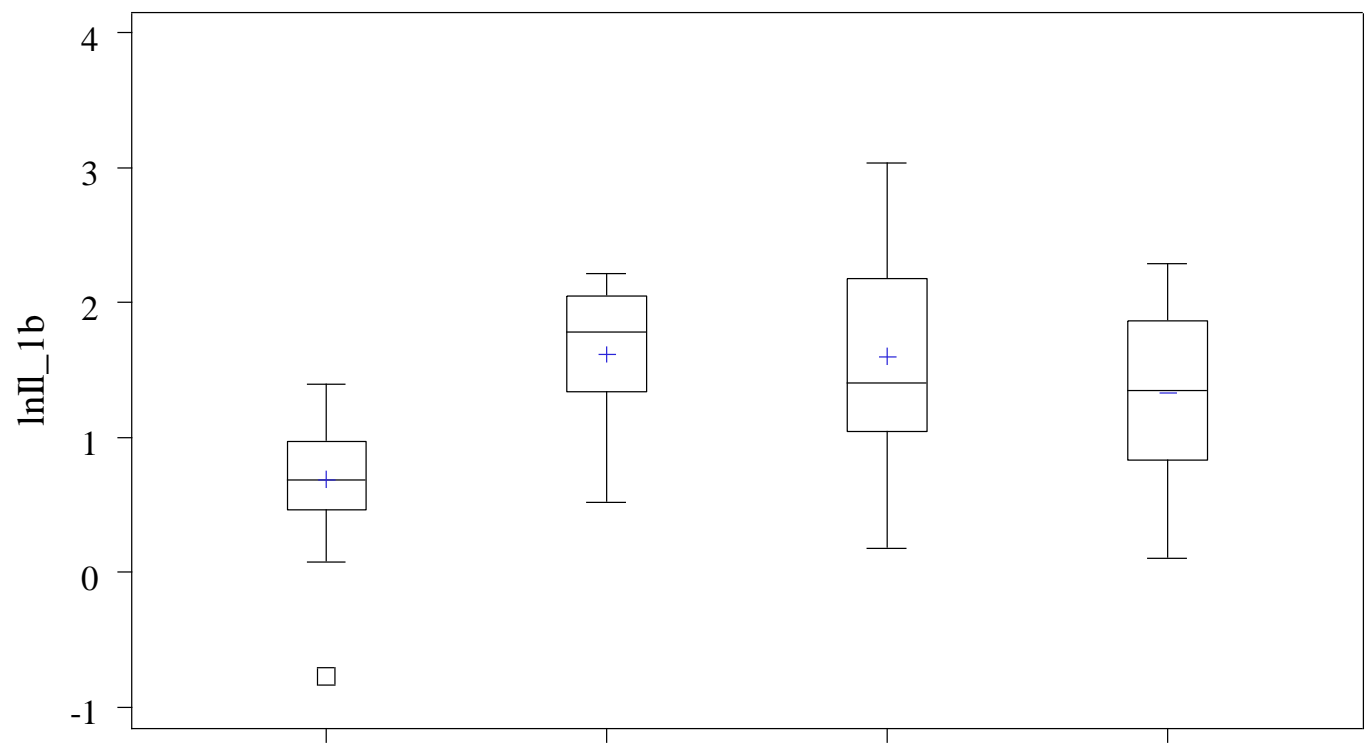

Control Exposed week $1 \quad$ Exposed week 2 Exposed week 3

week_type

g. G-CSF 


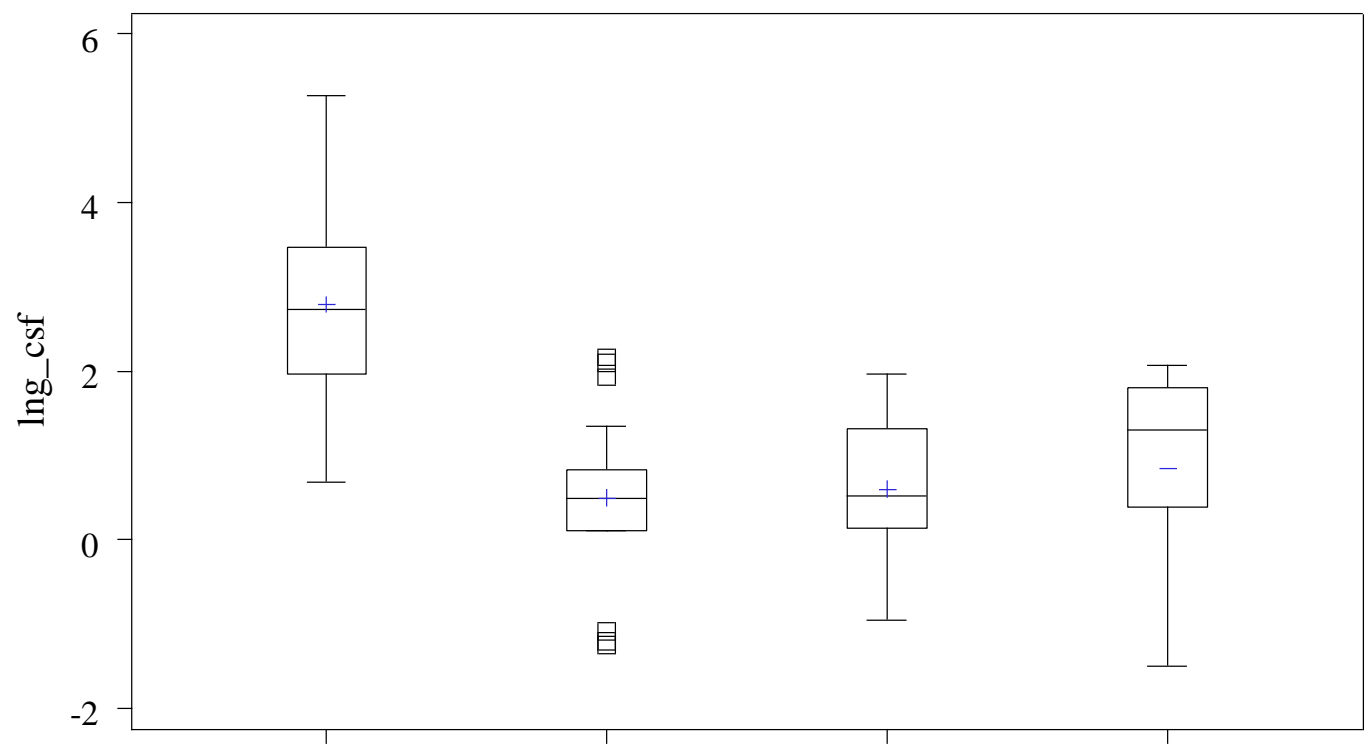

Control Exposed week $1 \quad$ Exposed week 2 Exposed week 3 week_type

h. IL-10

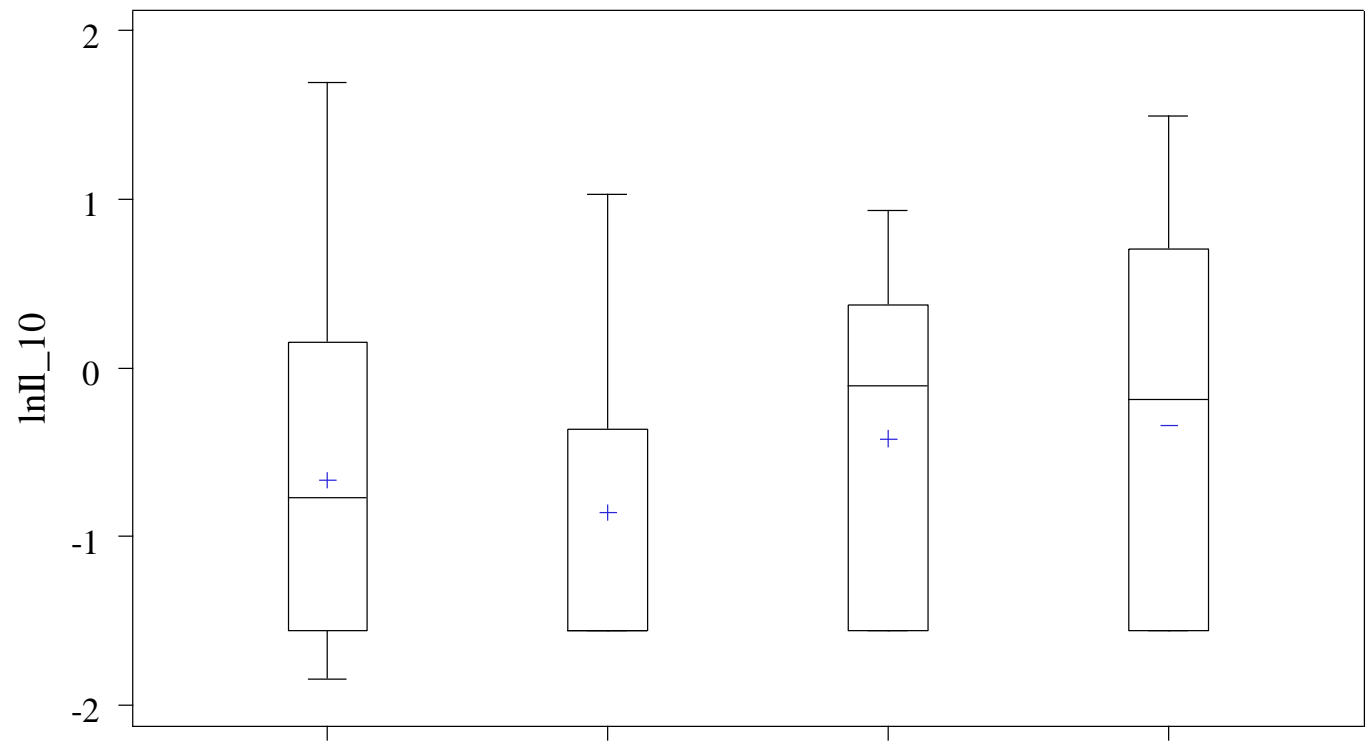

Control $\quad$ Exposed week $1 \quad$ Exposed week 2 Exposed week 3 week_type 
k. $8-\mathrm{OH}-\mathrm{dG}$

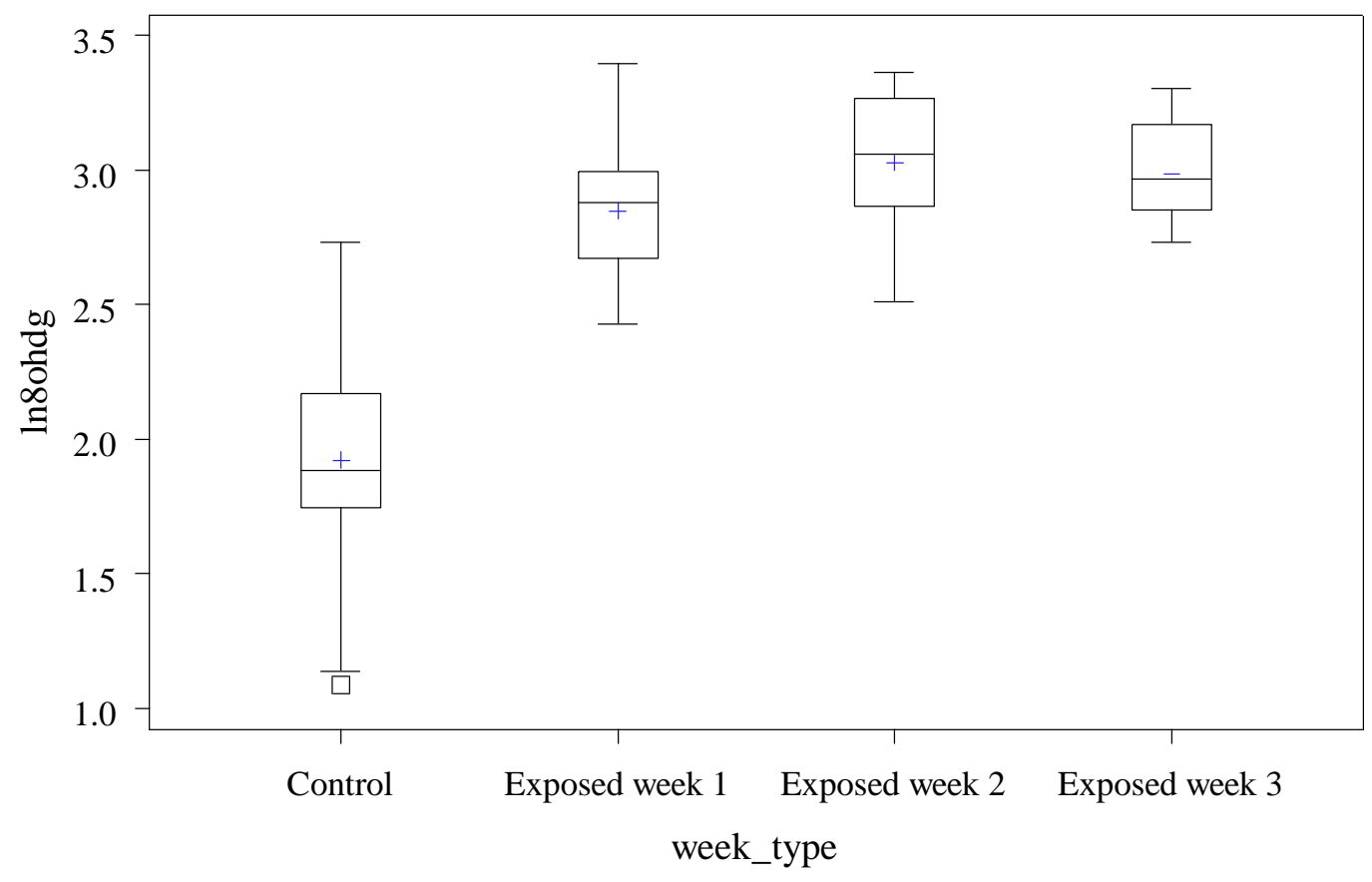




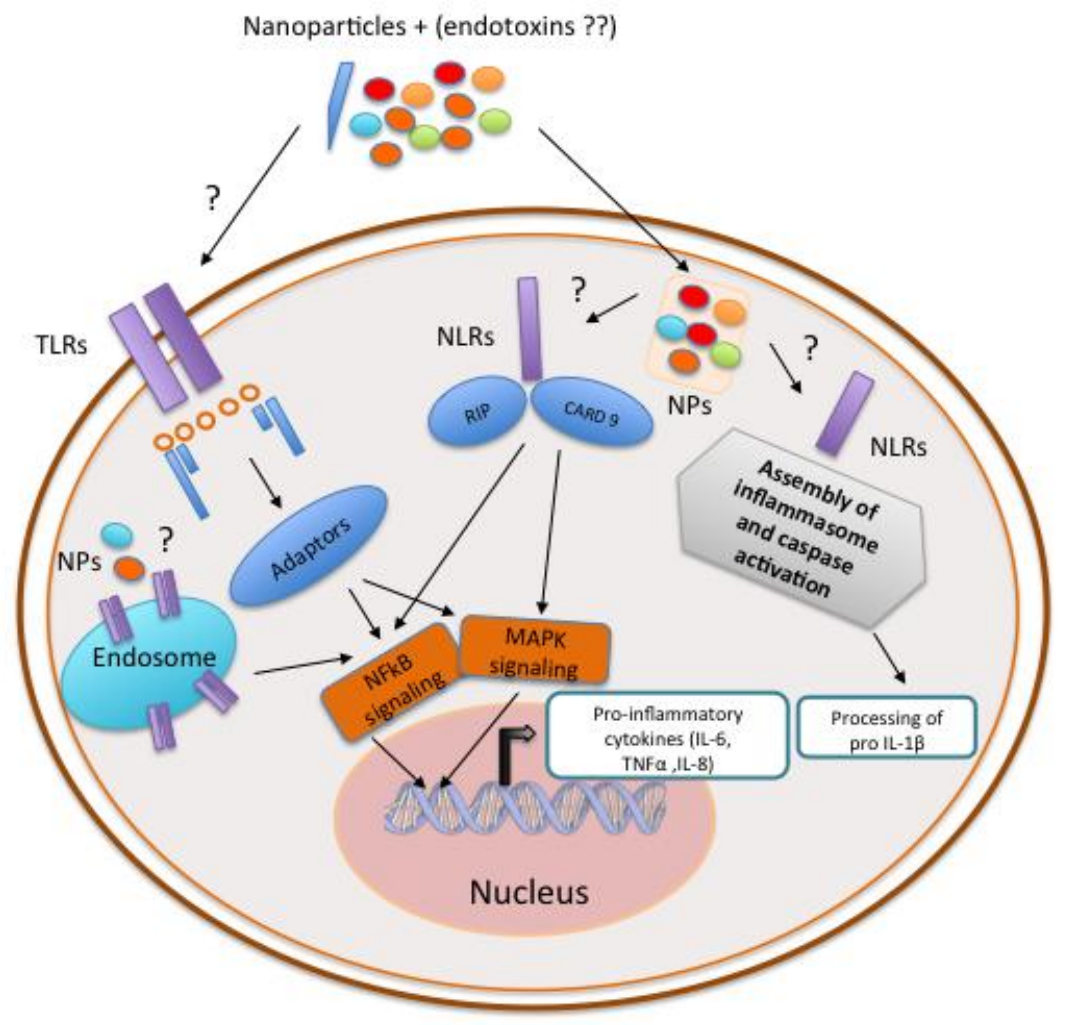

Figure 4. A proposed mechanism of copier and printer emitted nanoparticle-induced toxicity potentially involving multiple receptors, including surface expressed TLRs (e.g. TLR 4), endosomal residing TLRs (e.g. TLR 3, 7, 8 and 9) and Nod-like receptors (NLRs), leading to inflammasome and caspase activation, as well as NFkB and possible MAPK signaling. The mixed chemical exposure nature of these nanoparticles may involve additional molecular pathways. 


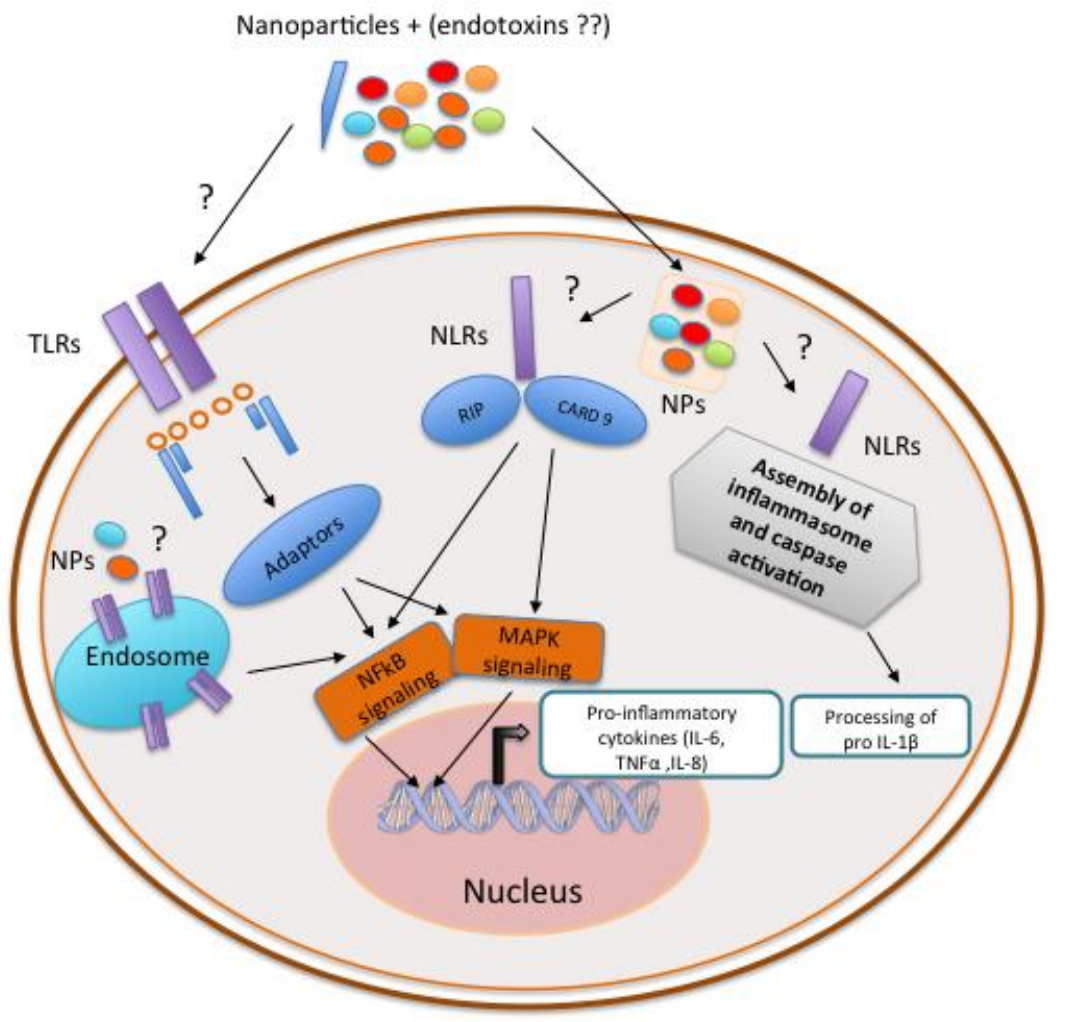

Figure 5 
Table 1. Demographic information for controls $(n=11)$ and photocopier operators $(n=6)$ enrolled in this study.

\begin{tabular}{|c|c|c|c|c|c|c|}
\hline $\begin{array}{l}\text { Chronically } \\
\text { Exposed } \\
\text { Copier } \\
\text { Operators }\end{array}$ & Center & $\begin{array}{l}\text { Age } \\
\text { (years) }\end{array}$ & $\begin{array}{l}\text { Gender } \\
\text { (M/F) }\end{array}$ & $\begin{array}{l}\text { Current } \\
\text { Smoker } \\
(\mathrm{Y} / \mathrm{N})^{1}\end{array}$ & $\begin{array}{l}\text { Years } \\
\text { at } \\
\text { work }\end{array}$ & Self-reported symptoms \\
\hline Subject 1 & $A$ & 52 & $\mathrm{~F}$ & $\mathrm{Y}$ & 15 & $\begin{array}{l}\text { Watery eyes during work hours, skin } \\
\text { darkening around the nose and cheeks }\end{array}$ \\
\hline Subject 2 & $A$ & 40 & $\mathrm{~F}$ & $\mathrm{~N}$ & 8 & $\begin{array}{l}\text { Headache during and after work day, } \\
\text { feels normal on holidays }\end{array}$ \\
\hline Subject 3 & $\mathrm{~B}$ & 55 & $\mathrm{~F}$ & $\mathrm{~N}$ & 6 & Anosmia (Loss of smell), Asthmatic \\
\hline Subject 4 & B & 34 & M & $\mathrm{N}$ & 2 & No symptoms reported \\
\hline Subject 5 & C & 42 & $\mathrm{~F}$ & $\mathrm{~N}$ & 5 & Eye irritation \\
\hline Subject 6 & C & 35 & M & $\mathrm{N}$ & 7 & $\begin{array}{l}\text { Dry mouth and headache, runny nose, } \\
\text { severe allergies }\end{array}$ \\
\hline $\begin{array}{l}\text { Exposed } \\
\text { mean } \\
\text { (range) } \\
\mathrm{n}=6\end{array}$ & & $\begin{array}{c}43.0 \\
(35- \\
57)\end{array}$ & $4 F, 2 M$ & $1 Y, 5 N$ & & \\
\hline $\begin{array}{l}\text { Controls } \\
\text { mean } \\
\text { (range) } \\
n=11\end{array}$ & & $\begin{array}{c}39.3 \\
(25- \\
61)\end{array}$ & $7 F, 4 M$ & $\mathbf{N}$ & & $\begin{array}{l}\text { Healthy individuals; No particular } \\
\text { symptoms were reported }\end{array}$ \\
\hline
\end{tabular}

1. Current smoker, defined as smoking during the past year, as well as during the study period.

2. For overall exposed and controls, we report mean age (yrs.), range, \%females, and a test for significance. 
Table 2. Weekly summary statistics of nanoparticle exposures at three high volume commercial photocopy centers in the Northeast.

\begin{tabular}{|c|c|c|c|c|c|c|c|}
\hline \multirow{2}{*}{$\begin{array}{l}\text { Center } \\
\text { ID }\end{array}$} & \multicolumn{5}{|c|}{ Total Particle Number Concentration $\left(\# / \mathrm{cm}^{3}\right)$} & \multirow{2}{*}{$\begin{array}{c}\text { Ratio } \\
\mathbf{G M}_{\mathrm{p}} / \mathbf{G M}_{\text {bkgd }}\end{array}$} & \multirow{2}{*}{$\begin{array}{c}\mathbf{P M}_{0.1} \\
\left(\mu \mathrm{gg} / \mathbf{m}^{3}\right)\end{array}$} \\
\hline & $\mathbf{A M}$ & GM & GSD & Max & $\begin{array}{c}\text { Range of daily } \\
\text { GM }\end{array}$ & & \\
\hline$\overline{\mathrm{A}}$ & 15614 & 13633 & 1.7 & 46000 & $8,859-23,612$ & 12.1 & 4.5 \\
\hline $\mathrm{B}$ & 14641 & 12966 & 1.7 & 62600 & $4,274-15,264$ & 1.7 & 2.2 \\
\hline $\mathrm{C}$ & 21869 & 11435 & 2.9 & 143000 & $4,895-30,795$ & 3.5 & 2.2 \\
\hline
\end{tabular}

Legend: AM, Arithmetic mean; GM, Geometric mean; GSD, Geometric standard deviation; Max, Maximum measured concentration. The GM and GSD were estimated after accounting for the autocorrelation of the real-time data. $\mathrm{GM}_{\mathrm{p}} / \mathrm{GM}_{\mathrm{bkgd}}$ is the ratio of the geometric mean of exposure distributions relative to the background values collected prior to the beginning of the work day. Reproduced with permission of Martin et al. [2]. 
Table 3. Magnetic sector inductively coupled plasma mass spectrometry (SF-ICP-MS) analysis of the nanoscale aerosol fraction collected with the Harvard Compact Cascade Impactor (CCI). Elemental analysis included 47 elements, of which the most abundant are tabulated. Other elements tested were Ag, Cd, Ce, Co, Cs, Dy, Eu, Ho, La, Li, Nb, Pd, Pr, Pt, Rb, Rh, Sb, Sc, Sm , Sr, Th, Tl, U, Y and Yb.

\begin{tabular}{|c|c|c|c|c|c|c|c|c|c|c|c|c|c|c|c|c|}
\hline $\begin{array}{l}\text { Cen } \\
\text { ter } \\
\text { ID } \\
\end{array}$ & $\begin{array}{c}\text { Ele } \\
\text { ment }\end{array}$ & $\mathrm{Fe}$ & $\mathrm{Zn}$ & $\mathrm{Cu}$ & $\begin{array}{c}\mathbf{M} \\
\mathbf{n}\end{array}$ & Sn & $\mathrm{Cr}$ & $\mathbf{A l}$ & Mo & $\mathbf{C a}$ & $\mathbf{T i}$ & $\mathbf{N i}$ & $\mathbf{S}$ & As & $\mathbf{V}$ & $\mathbf{P b}$ \\
\hline \multirow[t]{2}{*}{1} & $\begin{array}{l}\text { Total } \\
(\mu \mathrm{g} / \\
\mathrm{g})\end{array}$ & $\begin{array}{l}28 \\
71\end{array}$ & $\begin{array}{c}72 \\
3\end{array}$ & $\begin{array}{c}15 \\
6\end{array}$ & 45 & 19 & 20 & $\begin{array}{c}77 \\
1\end{array}$ & 3.4 & $\begin{array}{l}24 \\
60\end{array}$ & $\begin{array}{c}18 \\
2\end{array}$ & 19 & $\begin{array}{l}83 \\
93\end{array}$ & 12 & 55 & 35 \\
\hline & (SD) & $\begin{array}{c}18 \\
0\end{array}$ & $\begin{array}{c}10 \\
9\end{array}$ & 9 & 3 & 3 & 2 & 71 & 0.5 & $\begin{array}{c}22 \\
3\end{array}$ & 16 & 3 & $\begin{array}{c}78 \\
4\end{array}$ & 3 & 4 & 2.8 \\
\hline \multirow[t]{2}{*}{2} & $\begin{array}{c}\text { Total } \\
(\mu \mathrm{g} / \\
\mathrm{g})\end{array}$ & $\begin{array}{l}29 \\
72\end{array}$ & $\begin{array}{l}15 \\
76\end{array}$ & $\begin{array}{c}18 \\
7\end{array}$ & 75 & 94 & 29 & $\begin{array}{c}92 \\
6\end{array}$ & $\begin{array}{c}25 . \\
5\end{array}$ & $\begin{array}{l}19 \\
47\end{array}$ & $\begin{array}{c}30 \\
8\end{array}$ & 97 & $\begin{array}{c}50 \\
45 \\
0\end{array}$ & 89 & $\begin{array}{c}13 \\
6\end{array}$ & $\begin{array}{c}84 \\
6\end{array}$ \\
\hline & (SD) & $\begin{array}{c}18 \\
6\end{array}$ & $\begin{array}{c}18 \\
4\end{array}$ & 10 & 5 & 6 & 3 & 84 & 2.3 & $\begin{array}{c}19 \\
4\end{array}$ & 31 & 9 & $\begin{array}{l}44 \\
62\end{array}$ & 10 & 9 & $\begin{array}{c}65 . \\
8\end{array}$ \\
\hline \multirow[t]{2}{*}{3} & $\begin{array}{l}\text { Total } \\
(\mu \mathrm{g} / \\
\mathrm{g})\end{array}$ & $\begin{array}{l}41 \\
00\end{array}$ & $\begin{array}{l}18 \\
10\end{array}$ & $\begin{array}{c}77 \\
8\end{array}$ & $\begin{array}{c}13 \\
2\end{array}$ & $\begin{array}{c}24 \\
3\end{array}$ & $\begin{array}{c}11 \\
0\end{array}$ & $\begin{array}{l}32 \\
40\end{array}$ & 27 & $\begin{array}{c}14 \\
50 \\
0\end{array}$ & $\begin{array}{c}54 \\
8\end{array}$ & $\begin{array}{c}88 . \\
7\end{array}$ & $\begin{array}{c}40 \\
10 \\
0\end{array}$ & 45 & $\begin{array}{c}24 . \\
5\end{array}$ & $\begin{array}{c}25 \\
0\end{array}$ \\
\hline & (SD) & $\begin{array}{c}18 . \\
4\end{array}$ & $\begin{array}{c}12 . \\
7\end{array}$ & $\begin{array}{c}2.6 \\
4\end{array}$ & $\begin{array}{c}0.7 \\
4\end{array}$ & 1.7 & $\begin{array}{c}0.8 \\
7\end{array}$ & $\begin{array}{c}21 . \\
6\end{array}$ & $\begin{array}{c}0.3 \\
7\end{array}$ & $\begin{array}{c}92 . \\
7\end{array}$ & $\begin{array}{c}6.3 \\
4\end{array}$ & $\begin{array}{c}1.1 \\
3\end{array}$ & $\begin{array}{c}28 \\
9\end{array}$ & $\begin{array}{c}0.7 \\
5\end{array}$ & $\begin{array}{c}0.3 \\
0\end{array}$ & $\begin{array}{c}1.2 \\
8\end{array}$ \\
\hline
\end{tabular}


Table 4. Summary statistics of the particle size distribution and multiple path particle deposition model estimates for human airways in the three high-volume commercial photocopy centers in the northeast United States. ${ }^{1}$ Percent particle deposition is based on particle number available for deposition as measured by real-time particle measuring instruments used during this study. CMD, Count median diameter (nm); MMD, Mass median diameter (nm). Deposition statistics derived with the Multiple Path Particle Dosimetry (MPPD) model software v. 2.1. Reproduced with permission from Martin et al. [2].

\begin{tabular}{|c|c|c|c|c|c|c|c|c|}
\hline \multirow{2}{*}{$\begin{array}{c}\text { Center } \\
\text { ID }\end{array}$} & \multirow{2}{*}{$\begin{array}{c}\text { CMD } \\
(\mathbf{n m})\end{array}$} & \multirow{2}{*}{$\sigma_{\mathrm{g}}$} & \multirow{2}{*}{$\begin{array}{c}\text { MMD } \\
(\mathbf{n m})\end{array}$} & \multirow{2}{*}{$\begin{array}{l}\text { Mass } \\
\text { Conc } \\
\mu \mathrm{g} / \mathbf{m}^{3}\end{array}$} & \multicolumn{4}{|c|}{ \% Deposition (number) } \\
\hline & & & & & Total $^{1}$ & Head & Thoracic & Alveolar \\
\hline A & 35.1 & 1.9 & 123.9 & 4.5 & 33.7 & 5.7 & 11.1 & 17.0 \\
\hline B & 23.1 & 2.1 & 113.2 & 2.2 & 35.9 & 6.2 & 12.1 & 17.9 \\
\hline $\mathrm{C}$ & 38.3 & 1.7 & 86.48 & 2.2 & 39.8 & 6.4 & 13.2 & 20.2 \\
\hline \multicolumn{4}{|c|}{ Human Model } & \multicolumn{5}{|c|}{ Breathing Parameters } \\
\hline \multicolumn{4}{|c|}{ Functional Residual Capacity: $3300.0 \mathrm{~mL}$} & \multicolumn{5}{|c|}{ Tidal Volume: $625 \mathrm{ml}$} \\
\hline \multicolumn{4}{|c|}{ Head Volume: $50 \mathrm{~mL}$} & \multicolumn{5}{|c|}{ Breathing Frequency: 12 breaths/ min } \\
\hline \multicolumn{4}{|c|}{ Breathing Route: Nasal } & \multicolumn{5}{|c|}{ Inspiratory Fraction: 0.5} \\
\hline & & & & \multicolumn{5}{|c|}{ Pause Fraction: 0.0} \\
\hline
\end{tabular}


Table 5: Summary statistics of the biomarker levels in the nasal lavage (cytokines, PMN, total proteins) and urine (8-OH-dG). All markers, except PMN are log normally distributed and expressed as mean of In (variable). The values are averaged across all three weeks. Weekly measurements for were collected on Monday morning before the start of work shift (Mo-AM), Monday afternoon at the end of the shift (Mo-PM) and Friday afternoon post-shift (Fri-PM). Sampling of controls was conducted during similar times.

\begin{tabular}{|c|c|c|c|c|c|}
\hline \multirow[t]{2}{*}{ BIOMARKER } & \multicolumn{2}{|c|}{$\begin{array}{c}\text { Controls } \\
\text { Overall NL }\end{array}$} & \multicolumn{2}{|c|}{$\begin{array}{c}\text { Chronically exposed workers } \\
\text { averaged over three weeks } \\
\text { NL }\end{array}$} & \multirow[t]{2}{*}{ P Value } \\
\hline & $\begin{array}{l}\text { Mean Ln } \\
(95 \% \text { CI })\end{array}$ & Min - Max & $\begin{array}{l}\text { Mean Ln } \\
(95 \% \text { CI })\end{array}$ & Min - Max & \\
\hline Total Proteins & $\begin{array}{c}5.83 \\
(5.62-6.05)\end{array}$ & $4.93-6.41$ & $\begin{array}{c}7.30 \\
(7.07-7.53)\end{array}$ & $6.96-7.93$ & $<.0001$ \\
\hline$\% P M N$ & $\begin{array}{c}14.87 \\
(10.96-18.77)\end{array}$ & $3.54-24.56$ & $\begin{array}{c}39.91 \\
(32.30-47.51)\end{array}$ & $24.57-60.32$ & $<.0001$ \\
\hline$E G F$ & $\begin{array}{c}4.44 \\
(3.91-4.97)\end{array}$ & $2.20-5.75$ & $\begin{array}{c}4.32 \\
(3.77-4.87)\end{array}$ & $2.09-5.92$ & 0.738 \\
\hline$G-C S F$ & $\begin{array}{c}2.79 \\
(2.11-3.46)\end{array}$ & $0.68-5.27$ & $\begin{array}{c}0.62 \\
(-0.22-1.45)\end{array}$ & $-1.50-2.17$ & $<.0001$ \\
\hline$G M-C S F$ & $\begin{array}{c}0.59 \\
(0.02-1.15)\end{array}$ & $-1.57-1.90$ & $\begin{array}{c}0.40 \\
(-0.07-0.87)\end{array}$ & $-1.02-2.33$ & 0.592 \\
\hline Fractalkine & $\begin{array}{c}4.34 \\
(3.85-4.83)\end{array}$ & $1.59-6.50$ & $\begin{array}{c}4.65 \\
(4.13-5.17)\end{array}$ & $2.30-6.69$ & 0.319 \\
\hline$I L-1 \alpha$ & $\begin{array}{c}4.10 \\
(3.68-4.52)\end{array}$ & $2.91-5.37$ & $\begin{array}{c}4.65 \\
(4.09-5.21)\end{array}$ & $3.13-6.32$ & 0.07 \\
\hline$I L-1 \beta$ & $\begin{array}{c}0.69 \\
(0.48-0.89)\end{array}$ & $-0.77-1.39$ & $\begin{array}{c}1.52 \\
(1.28-1.76)\end{array}$ & $0.10-3.03$ & $<.0001$ \\
\hline$I L-6$ & $\begin{array}{c}0.80 \\
(0.32-1.29)\end{array}$ & $-0.88-2.02$ & $\begin{array}{c}3.01 \\
(2.52-3.50)\end{array}$ & $2.17-4.35$ & $<.0001$ \\
\hline$I L-8$ & $\begin{array}{c}5.01 \\
(4.51-5.51)\end{array}$ & $2.90-4.48$ & $\begin{array}{c}7.51 \\
(7.20-7.81)\end{array}$ & $4.66-8.59$ & $<.0001$ \\
\hline$I L-10$ & $\begin{array}{c}-0.67 \\
(-1.13--0.21)\end{array}$ & $-1.84-1.69$ & $\begin{array}{c}-0.64 \\
(-1.49-0.20)\end{array}$ & $-1.56-1.49$ & 0.929 \\
\hline
\end{tabular}




\begin{tabular}{|c|c|c|c|c|c|}
\hline TNF- $\alpha$ & -0.49 & $-2.04-1.26$ & $\begin{array}{c}1.30 \\
(1.04-1.55)\end{array}$ & $0.34-3.15$ & $<.0001$ \\
\hline IFNy & $-1.06-0.09)$ & & -1.78 \\
& $(-2.04--0.73)$ & $-2.66-0.61$ & $-2.66-1.82$ & 0.277 \\
& & & $\begin{array}{c}-2.30- \\
2.27)\end{array}$ & \\
\hline MCP-1 & 4.20 & $2.15-6.01$ & 4.83 & $4.04-5.96$ & 0.156 \\
& $(3.53-4.88)$ & & $(4.33-5.33)$ & & \\
\hline VEGF & 3.54 & $0.87-5.06$ & $\begin{array}{c}3.96 \\
(2.82-5.11)\end{array}$ & $1.54-6.79$ & 0.346 \\
\hline Eotaxin & $(3.04-4.04)$ & & 2.34 & $0.64-3.87$ & 0.032 \\
& $(0.78-2.00)$ & $0.64-4.13$ & $(1.49-3.18)$ & & \\
\hline Urine & 1.92 & $1.09-2.73$ & $\begin{array}{c}2.91 \\
(2.68-3.13)\end{array}$ & $2.43-3.40$ & $<.0001$ \\
\hline- OH- $d G$ & $(1.65-2.19)$ & & & \\
\hline
\end{tabular}


Table 6. Summary statistics of weekly averages and ranges for nasal lavage (cytokines, PMN, total proteins) and urine (8-OH-dG) biomarkers. All variables are reported as Ln(variable), except for \% PMN, which was normally distributed and not transformed. Weekly measurements were collected on Monday morning before the start of work shift (MoAM), Monday afternoon at the end of the shift (Mo-PM) and Friday afternoon post-shift (Fri$\mathrm{PM})$.

\begin{tabular}{|c|c|c|c|c|c|c|c|}
\hline \multirow{2}{*}{ BIOMARKER } & \multicolumn{2}{|c|}{ Week 1} & \multicolumn{2}{|c|}{ Week 2} & \multicolumn{2}{|c|}{ Week 3} & \multirow{2}{*}{$\begin{array}{c}\mathbf{P} \\
\text { Value } \\
\end{array}$} \\
\hline & $\begin{array}{c}\text { Mean } \\
\text { Ln } \\
(95 \\
\% \text { CI })\end{array}$ & $\begin{array}{l}\text { Min - } \\
\text { Max }\end{array}$ & $\begin{array}{c}\text { Mean Ln } \\
(95 \% \mathrm{CI})\end{array}$ & $\begin{array}{l}\text { Min - } \\
\text { Max }\end{array}$ & $\begin{array}{c}\text { Mean Ln } \\
(95 \% \mathrm{CI})\end{array}$ & $\begin{array}{l}\text { Min - } \\
\text { Max }\end{array}$ & \\
\hline Total Proteins & $\begin{array}{c}7.37 \\
(7.08- \\
7.67)\end{array}$ & $7.05-7.93$ & $\begin{array}{c}7.28 \\
(6.98-7.58)\end{array}$ & $6.98-7.69$ & $\begin{array}{c}7.25 \\
(7.02-7.49)\end{array}$ & $6.96-7.56$ & 0.243 \\
\hline$\% P M N$ & $\begin{array}{c}38.73 \\
(30.37- \\
47.10) \\
\end{array}$ & $\begin{array}{c}24.57- \\
60.32\end{array}$ & $\begin{array}{c}42.18 \\
(32.43- \\
51.92) \\
\end{array}$ & $\begin{array}{c}27.89- \\
54.51\end{array}$ & $\begin{array}{c}42.25 \\
(31.07- \\
53.43) \\
\end{array}$ & $\begin{array}{c}28.36- \\
56.81\end{array}$ & 0.689 \\
\hline$E G F$ & $\begin{array}{c}4.14 \\
(3.29- \\
4.50) \\
\end{array}$ & $2.21-5.71$ & $\begin{array}{c}4.36 \\
(3.64-5.09)\end{array}$ & $2.09-5.75$ & $\begin{array}{c}4.53 \\
(3.76-5.29)\end{array}$ & $3.63-5.93$ & 0.282 \\
\hline$G-C S F$ & $\begin{array}{c}0.50 \\
(-0.51- \\
1.50)\end{array}$ & $\begin{array}{c}-1.24- \\
2.17\end{array}$ & $\begin{array}{c}0.60 \\
(-0.39- \\
1.59)\end{array}$ & $-0.96-1.97$ & $\begin{array}{c}0.85 \\
(-0.77-2.49)\end{array}$ & $-1.50-2.07$ & 0.439 \\
\hline$G M-C S F$ & $\begin{array}{c}0.55 \\
(-0.4- \\
1.14) \\
\end{array}$ & $\begin{array}{l}-1.02- \\
2.33\end{array}$ & $\begin{array}{c}0.29 \\
(-0.31- \\
0.88) \\
\end{array}$ & $-0.51-1.90$ & $\begin{array}{c}0.28 \\
(-0.81-1.38)\end{array}$ & $-0.77-1.90$ & 0.630 \\
\hline Fractalkine & $\begin{array}{c}4.67 \\
(4.06- \\
5.28)\end{array}$ & $3.23-5.23$ & $\begin{array}{c}4.48 \\
(3.27-5.68)\end{array}$ & $2.30-5.85$ & $\begin{array}{c}4.74 \\
(3.87-5.62)\end{array}$ & $3.23-6.69$ & 0.589 \\
\hline$I L-1 \alpha$ & $\begin{array}{c}4.66 \\
(4.21- \\
5.12) \\
\end{array}$ & $3.99-5.76$ & $\begin{array}{c}4.74 \\
(4.03-5.46)\end{array}$ & $3.87-6.32$ & $\begin{array}{c}4.57 \\
(3.63-5.51)\end{array}$ & $3.13-6.27$ & 0.475 \\
\hline$I L-1 \beta$ & $\begin{array}{c}1.61 \\
(1.29- \\
1.93) \\
\end{array}$ & $0.52-2.12$ & $\begin{array}{c}1.60 \\
(0.83-2.36)\end{array}$ & $0.18-3.04$ & $\begin{array}{c}1.32 \\
(0.66-1.98)\end{array}$ & $0.10-2.29$ & 0.390 \\
\hline$I L-6$ & $\begin{array}{c}3.07 \\
(2.57- \\
3.57) \\
\end{array}$ & $2.18-4.35$ & $\begin{array}{c}3.02 \\
(2.30-3.73)\end{array}$ & $2.27-4.03$ & $\begin{array}{c}2.97 \\
(2.29-3.65)\end{array}$ & $2.17-4.11$ & 0.423 \\
\hline$I L-8$ & $\begin{array}{c}7.30 \\
(6.93- \\
7.67) \\
\end{array}$ & $6.63-8.23$ & $\begin{array}{c}7.56 \\
(6.88-8.24)\end{array}$ & $4.66-8.50$ & $\begin{array}{c}7.73 \\
(7.11-8.33)\end{array}$ & $6.64-8.59$ & 0.215 \\
\hline$I L-10$ & $\begin{array}{c}-0.86 \\
(-1.90- \\
0.18) \\
\end{array}$ & $\begin{array}{c}-1.56- \\
1.03\end{array}$ & $\begin{array}{c}-0.42 \\
(-1.75- \\
0.91)\end{array}$ & $-1.56-0.93$ & $\begin{array}{c}-0.34 \\
(-0.77-1.08)\end{array}$ & $-1.56-1.49$ & 0.330 \\
\hline$T N F-\alpha$ & 1.47 & $0.46-3.15$ & 1.10 & $0.34-2.08$ & 1.29 & $0.53-2.19$ & 0.160 \\
\hline
\end{tabular}




\begin{tabular}{|c|c|c|c|c|c|c|c|}
\hline & $(0.84-$ & & $(0.74-1.45)$ & & $(0.79-1.80)$ & & \\
\hline IFNy & $2.10)$ & & & & & & \\
& -1.70 & $-2.66-$ & -1.32 & $-2.66-1.81$ & -2.34 & $-2.66-(-$ & 0.049 \\
& $(-2.77)-$ & 1.09 & $(-2.90-$ & & $(-2.90)-$ & $1.42)$ & \\
& $(-0.62)$ & & $0.27)$ & & $(1.78)$ & & \\
\hline MCP-1 & 4.75 & $4.04-5.53$ & 5.03 & $4.10-5.96$ & 4.90 & $4.17-5.65$ & 0.273 \\
& $(4.29-$ & & $(4.24-5.82)$ & & $(4.35-5.44)$ & & \\
& $5.21)$ & & & & & & \\
\hline VEGF & 3.98 & $2.17-6.29$ & 4.19 & $2.10-6.79$ & 3.93 & $1.54-6.27$ & 0.778 \\
& $(2.70-$ & & $(2.18-6.02)$ & & $(2.47-5.38)$ & & \\
\hline Eotaxin & $5.25)$ & & & & & & \\
& 2.42 & $0.64-3.87$ & 2.29 & $0.64-3.74$ & 2.17 & $0.64-3.79$ & 0.786 \\
& $(1.26-$ & & $(1.08-3.51)$ & & $(1.31-3.21)$ & & \\
\hline $8-O H-d G$ & $3.58)$ & & & & & & \\
& 2.85 & $2.43-3.40$ & 3.03 & $2.51-3.36$ & 2.99 & $2.72-3.30$ & 0.236 \\
& $(2.56-$ & & $(2.69-3.36)$ & & $(2.81-3.17)$ & & \\
\hline
\end{tabular}

